\title{
Using Mandated Speed Limits to Measure the Value of a Statistical Life*
}

\author{
Orley Ashenfelter \\ Princeton University \\ Michael Greenstone \\ University of Chicago
}

April 2002

* We thank Gary Becker, Glenn Blomquist, David Card, Mark Duggan, David Lee, Helen Levy, Alan Manning, Will Manning, Enrico Moretti, Casey Mulligan, Kevin Murphy, Anne Piehl, and W. Kip Viscusi for valuable comments. Numerous seminar participants provided very helpful suggestions. Michael Park and Anand Dash deserve special thanks for superb research assistance. We acknowledge generous financial support from the Industrial Relations Section at Princeton and the Robert Wood Johnson Foundation. 


\title{
Using Mandated Speed Limits to Measure the Value of a Statistical Life
}

\begin{abstract}
In 1987 the federal government permitted states to raise the speed limit on their rural interstate roads, but not on their urban interstate roads, from $55 \mathrm{mph}$ to $65 \mathrm{mph}$ for the first time in over a decade. Since the states that adopted the higher speed limit must have valued the travel hours they saved more than the fatalities incurred, this experiment provides a way to estimate an upper bound on the public's willingness to trade off wealth for a change in the probability of death. We find that the $65 \mathrm{mph}$ limit increased speeds by approximately 3.5\% (i.e., $2 \mathrm{mph}$ ), and increased fatality rates by roughly $35 \%$. In the 21 states that raised the speed limit and for whom we have complete data, the estimates suggest that about 125,000 hours were saved per lost life. Valuing the time saved at the average hourly wage implies that adopting states were willing to accept risks that resulted in a savings of $\$ 1.54$ million (1997\$) per fatality, with a sampling error that might be around one-third this value. Since this estimate is an upper bound of the value of a statistical life (VSL), we set out a simple structural model that is identified by variability across the states in the probability of the adoption of increased speed limits to recover the VSL. The empirical implementation of this model produces estimates of the VSL that are generally smaller than $\$ 1.54$ million, but these estimates are very imprecise.
\end{abstract}

Orley Ashenfelter

Industrial Relations Section

Princeton University

Firestone Library

Princeton, NJ 08544-2098

and NBER

c6789@alfa.princeton.edu
Michael Greenstone

Department of Economics

University of Chicago

1126 E. $59^{\text {th }}$ Street

Chicago, IL 60637

and NBER

mgreenst@midway.uchicago.edu 
Public choices about safety in a democratic society require estimates of the willingness of people to trade off wealth for a reduction in the probability of death. In this paper we exploit a novel opportunity to measure the revealed preferences for safety risks from public choices about speed limits. The idea is to measure the value of the time saved per incremental fatality that results from the voluntary adoption of an increased speed limit. Since adopters must have valued the time saved by greater speeds more than the fatalities created, this ratio provides a convincing and credible upper bound on the value of a statistical life (VSL).

Although there have been a number of creative attempts designed to estimate the value of a statistical life, ${ }^{1}$ there have been few opportunities to obtain estimates based on the public's willingness to accept an exogenous and known safety risk. Our analysis exploits the opportunity that the federal government gave the states in 1987 to choose a speed limit for rural interstate highways that was higher than the uniform national maximum speed limit then in existence. This remarkable experiment led 40 of the 47 states that have rural interstate highways to adopt 65 mile per hour (mph) speed limits on them, while the remaining 7 states retained 55 mph speed limits.

This institutional change permits us to address several conceptual problems that have plagued previous attempts to estimate the value of a statistical life. First, the earliest estimates of the value of a statistical life were based on hedonic wage equations that many observers acknowledge suffer from severe omitted variables biases. ${ }^{2}$ The 1987 change in speed limits provides an exogenous change that avoids the difficulties inherent in making causal inferences with observational data on individuals' past optimizing decisions. Moreover, our estimates of the tradeoffs between the value of time saved and fatalities can be made both from comparisons of rural interstate highways across states that altered their speed limits with those that did not and from comparisons of rural interstates and other highways within states that adopted increased speeds. This statistical design provides many alternative estimates of the actual tradeoff between

\footnotetext{
${ }^{1}$ For useful, detailed surveys see Viscusi (1993) and Blomquist (2001). Also see de Blaeij, et al. (2000) for a formal meta-analysis of the value of a statistical life from studies of road safety.

${ }^{2}$ See especially Hersch (1998), who documents that for male blue collar workers injury risks are usually estimated as negatively related to wage rates, implying VSL estimates that are also negative. This finding is universally interpreted to result from the difficulty in properly specifying and measuring the key variables that enter wage equations.
} 
the value of travel time and fatalities and thus provides many tests of the consistency of the estimates.

Second, many questions have been raised about the usefulness of studies of the value of a statistical life when the decision makers studied may be poorly informed about the relevant risks. We show that the relevant decision makers (i.e., state governments) were cognizant of the tradeoffs associated with a change in speed limits. Although this does not provide conclusive evidence that the participants in the decisions were well informed, it is certainly more plausible than is often the case.

Third, any VSL estimate that is based on the decisions of a third party (e.g., government policies) may not reflect the preferences of the group whose VSL is of interest. For example, federal regulatory agencies, such as the Environmental Protection Agency and Federal Aviation Administration, regularly assess prospective safety projects. Since the benefits and costs of these regulations are borne by entirely different groups, the agency's decisions may be seriously distorted by the inevitable political process by which they are determined. It seems likely that the substantial heterogeneity both across and within the cost per life saved in enacted safety projects shown by Viscusi (2000) reflects these problems. Speed limit regulations, however, provide benefits (reduced travel time) and costs (fatality risk) to precisely the same people, so that appeals to a simple model of the typical voter are far more plausible in this context.

Finally, in studies of safety risks in the market place it is inevitably the VSL of a selected group of individuals that place a low valuation on increased risks that is measured, since they will be the marginal adopters. These individuals' VSL will rarely be the appropriate one for evaluating policies that affect a broader cross-section of the population. In contrast, this paper presents a simple individual-level behavioral model that predicts that the median voter's/driver's preferences determine which states adopt the higher limit. We provide evidence that is consistent with this behavioral interpretation of the results.

Our empirical results indicate that among states that adopted increased speed limits on their rural interstates, average speeds increased by approximately 3.5\% (i.e., $2 \mathrm{mph}$ ) while fatality rates increased by roughly $35 \%$. In the 21 states that raised the speed limit and for whom we have complete data, the estimates suggest that there were an additional 45 million hours 
saved and 360 lives lost annually, which translate into 125,000 hours per life. These two effects are estimated reasonably precisely and the key inferences are similar across many different specifications.

Valuing the time saved from increased speeds at the average hourly wage implies that adopting states were willing to accept risks that resulted in a saving of \$1.54 million (1997\$) per fatality. Since this figure is the value of time saved per marginal fatality among states adopting higher speed limits, it provides an upper bound on the VSL in the adopting states. We set out a simple structural model that is identified by variability across the states in the probability of the adoption of increased speed limits to recover the VSL. The empirical implementation of this model produces estimates of the VSL that are generally smaller than $\$ 1.54$ million, but these estimates are very imprecise.

The plan of the paper is as follows: Section I sets out the conceptual rationale for a simple econometric model that may be used to estimate the tradeoff between risk and wealth. Section II provides a brief history of speed limits and describes how the 1987 law can be used to estimate the VSL. Section III describes the data sources, presents the key descriptive statistics, and reports the unadjusted estimates of the effects of the $65 \mathrm{mph}$ speed limit on fatalities and speeds. Section IV lays out the econometric framework for a structural model of safety decisions. Section V presents our estimates of the value of time saved per marginal fatality, while Section VI reports on our efforts to obtain an estimate of the value of a statistical life. Finally, a discussion of the primary results and some of their major limitations in Section VII is followed by a brief conclusion.

\section{Conceptual Framework}

In order to see how empirical estimates of the effect of speed limits on speeds and fatalities provide a way to quantify the revealed preferences of the median driver/voter for safety, it is useful to set up a simple explicit model of behavior

\section{A. Selecting an Optimal Speed}

The first order effect of traveling at a higher speed is a change in travel times for each mile traveled by each driver and a corresponding change in the likelihood of a fatality. This 
ignores the altered costs of fuel and other driving costs from altered speeds. These incremental costs, as noted by Ghosh, Lees, and Seal (1975), are very small compared to the time costs.

To provide a dollar measure of the value of life, it is necessary to provide a dollar value to the benefits of travel. To do this write $\mathrm{h}$ for the hours spent traveling m miles so that $(\mathrm{h} / \mathrm{m})=$ $(1 / \mathrm{s})$ is the average hours required to travel $\mathrm{m}$ miles per driver. $(\mathrm{h} / \mathrm{m})$ is, of course, the reciprocal of the average speed (s) on the road. If the cost of an hour of time spent traveling is w, then the average cost of a mile of travel time per driver is

$$
\mathrm{c}=\mathrm{w}(\mathrm{h} / \mathrm{m}) \text {. }
$$

$\mathrm{c}$ is also a measure of the value of a mile spent traveling. After all, if a mile of travel were not worth at least $\mathrm{c}$, it would not be undertaken.

The appropriate way to measure the cost of time can be controversial. For most workers, however, a natural measure of the value (or cost) of their time is their wage rate. In the empirical work reported below, we use the mean wage rate in adopting states as a measure of the value of time, but our primary measurement methods do not depend on this assumption and other values may be used where appropriate. For some cases, it may be thought that a value less than the wage rate is appropriate. ${ }^{3}$ Virtually any measure of the cost of a worker's time, however, will be closely linked to a worker's wage.

Selecting a speed balances the desire to reduce the cost (c) of travel time by increasing speed (s) against the risks of increased fatalities that may exist from greater speeds. The full costs of travel are then

$$
\mathrm{g}=\mathrm{g}(\mathrm{c}, \mathrm{f}(\mathrm{c} / \mathrm{w}))
$$

where $g_{1}>0, g_{2}>0$, and $f=(F / m)$ is fatalities $(F)$ per mile and the function $\mathrm{f}(\mathrm{c} / \mathrm{w})=\mathrm{f}(\mathrm{h} / \mathrm{m})=$ $\mathrm{f}(1 / \mathrm{s})$, with $\mathrm{f}^{\prime}<0$, indicates how fatalities increase with speeds. ${ }^{4}$

3 See Beesley (1965), Lee and Dalvi (1971), Domencich and McFadden (1975), Deacon and Sonstelie (1985), and Waters (1996).

${ }^{4}$ This model is based on the assumption that vehicle miles traveled are fixed and independent of speed limits. It is a straightforward matter to extend the model to include the value of miles traveled as a separate component of welfare. Moreover, the evidence available is consistent with this approach. Greenstone (2002) uses data from 1982-90 and finds that vehicle miles of travel on rural interstates did not increase in states that adopted the $65 \mathrm{mph}$ speed limit. We extended this analysis to the length of our sample (1982-93) and reach a similar conclusion (the results are available upon request). 
The effect of a decrease in travel time on the total costs of travel time per mile is

$$
\mathrm{dg} / \mathrm{d}(\mathrm{h} / \mathrm{m})=\mathrm{g}_{1} \mathrm{~W}+\mathrm{g}_{2} \mathrm{f} .
$$

At low levels of speed, increases in speed presumably reduce time costs $\left(\mathrm{g}_{1} \mathrm{w}\right)$ by more than the increased accident costs ( $\mathrm{g}_{2} \mathrm{f}$ '). Thus, a small increase in speed, ds, that leads to a decrease in travel time of $\mathrm{dh}$ and an increase in fatalities of $\mathrm{df}$ is desirable if $-\mathrm{g}_{1} \mathrm{wdh}>\mathrm{g}_{2} \mathrm{df}$, which is satisfied when

$$
-w(d h / d f)>\left(g_{2} / g_{1}\right) .
$$

The speed that minimizes the full time and accident costs of travel, if it exists, satisfies

$$
\mathrm{V} \equiv-\mathrm{w} / \mathrm{f}^{\prime}=\left(\mathrm{g}_{2} / \mathrm{g}_{1}\right) \equiv \mathrm{V}^{*} \text {. }
$$

When (5) is satisfied, the monetary value of the extra time saved per marginal fatality, $\mathrm{V} \equiv \mathrm{w} / \mathrm{f}$ ', is just equal to the rate of substitution between monetary travel costs and fatalities, $\mathrm{V}^{*} \equiv\left(\mathrm{g}_{2} / \mathrm{g}_{1}\right)$.

The rate of substitution between monetary travel time costs and fatalities, $\mathrm{V}^{*} \equiv\left(\mathrm{g}_{2} / \mathrm{g}_{1}\right)$, is often called the value of a statistical life. ${ }^{5}$ This interpretation is derived from the fact that increases in speeds that decrease the cost of travel time per incremental fatality by more (less) than $\mathrm{V}^{*}$ will decrease (increase) the full costs of travel. A driver who minimizes the full cost of travel would correspondingly increase (or decrease) speeds according to whether the monetary value of time saved per fatality were greater or less than $\left(\mathrm{g}_{2} / \mathrm{g}_{1}\right)$, the implied monetary value of a life.

\section{B. Optimal Speed Limits}

The above discussion shows how an individual driver should determine his or her optimal speed, but it provides no rationale for the existence of speed limits. In fact, legally enforced speed limits are a result of the externality present because the probability of a fatality depends not only on a driver's own decision about the speed of travel, but also on the decisions of other drivers. The setting of a speed limit is, therefore, a political decision and this is widely recognized by traffic safety regulators. For example, an Indiana Department of Transportation report on speed limits concludes that:

"Speed limits represent trade-offs between risk and travel time for a road class or specific highway section reflecting an appropriate balance between the societal [emphasis added] goals of safety and mobility. The

\footnotetext{
${ }^{5}$ See especially Thaler and Rosen (1976) and Viscusi (1993).
} 
process of setting speed limits is not merely a technical exercise. It involves value judgments and trade-offs that are in the arena of the political process" (Khan, Sinha, and McCarthy, 2000, p. 144).

It follows that the appropriate specification of equation (2) for individual $i$ will depend on the speed limit $(\mathrm{L})$ through its effect on the $\mathrm{i}^{\text {th }}$ driver's speed, but also on the risk of a fatality resulting from other drivers' responses to $\mathrm{L}$. This is denoted as

$$
\mathrm{g}^{\mathrm{i}}=\mathrm{g}^{\mathrm{i}}\left(\mathrm{c}^{\mathrm{i}}(\mathrm{L}), \mathrm{f}^{\mathrm{i}}((\mathrm{c} / \mathrm{w})(\mathrm{L}))\right.
$$

where $c^{i}(L)$ indicates the effect of the speed limit on the $i^{\text {th }}$ driver's average cost of a mile traveled and $\mathrm{f}^{\mathrm{i}}((\mathrm{c} / \mathrm{w})(\mathrm{L}))$ shows how the $\mathrm{i}^{\text {th }}$ driver's probability of a fatality depends on the speed limit $\mathrm{L}$ (through the vector of speeds $(\mathrm{c} / \mathrm{w})(\mathrm{L})$ ). From the point of view of the $\mathrm{i}^{\text {th }}$ driver, the optimal speed limit balances the decreased cost of a mile traveled against his or her increased fatality risk, which is satisfied when

$$
\mathrm{V}^{\mathrm{i}} \equiv-\mathrm{w}^{\mathrm{i}} /\left(\mathrm{df}^{\mathrm{i}} / \mathrm{dL}\right)=\left(\mathrm{g}^{\mathrm{i}}{ }_{2} / \mathrm{g}^{\mathrm{i}}{ }_{1}\right) \equiv \mathrm{V}^{* \mathrm{i}} .
$$

The key implication of this analysis of the social decision about speed limits is that the observed result reflects the value of a statistical life for the person whose views are reflected in the political process. Black (1948) shows that in the absence of non-political frictions, the driver/voter whose interests are reflected in the social decision is likely to be positioned in the center of the distribution of preferences for safety, as no other decision will be more politically acceptable. ${ }^{6}$ Consequently, this model indicates that our empirical analysis should be interpreted as an analysis of the preferences of the median, or politically representative driver/voter.

\section{The Value of a Statistical Life and Mandatory Speed Limits}

A key point of the previous discussion is that measures of the monetary value of time saved per fatality as a result of a speed increase do not provide a measure of the value of a statistical life, $\mathrm{V}^{*}$. In general, such measures provide only a bound to the value of a statistical life.

Suppose, for example, the median driver/voter is offered the opportunity to increase the speed limit from $\overline{\mathrm{S}}$ to $\overline{\mathrm{S}}$, through the political process. Associated with this offer is a decrease

\footnotetext{
${ }^{6}$ Black (1948) shows that if choices are unidimensional and preferences are single-peaked, the median voter's preferences will determine the social decision.
} 
in the cost of travel time of $\mathrm{w} \Delta \mathrm{h}_{\mathrm{i}}$, in location $\mathrm{i}$, and an increase in fatalities of $\Delta \mathrm{f}_{\mathrm{i}}$, so that we may write

$$
\begin{aligned}
\mathrm{V}_{\mathrm{i}} & =-\mathrm{w}\left(\Delta \mathrm{h}_{\mathrm{i}} / \Delta \mathrm{f}_{\mathrm{i}}\right) \\
& =\alpha+\beta \mathrm{Z}_{\mathrm{i}}+\varepsilon_{\mathrm{i}},
\end{aligned}
$$

where $Z_{\mathrm{i}}$ and $\varepsilon_{\mathrm{i}}$ index observable and unobservable factors that make the effects of a speed limit increase more or less costly per fatality. The left hand side of equation (6) is a discrete measure of $\mathrm{V}$ in equation (5).

We assume the value of a statistical life, $V^{*}$ in equation (5), for the median voter/driver in state $\mathrm{i}$ can be approximated by

$$
\mathrm{V}_{\mathrm{i}}^{*}=\alpha^{\prime}+\beta^{\prime} \mathrm{X}_{\mathrm{i}}+\varepsilon_{\mathrm{i}},
$$

where $\mathrm{X}_{\mathrm{i}}$ and $\varepsilon_{\mathrm{i}}$ ' index observable and unobservable factors that influence the value of a statistical life. From the inequality (4), it follows that a higher speed limit will be adopted if $V_{i}>$ $\mathrm{V}_{\mathrm{i}}{ }^{*}$, for in this case the time costs saved by the higher speeds that result from the higher speed limit will be greater per fatality than the value of the median statistical life, $\mathrm{V}_{\mathrm{i}}{ }^{*}$. The probability that the higher speed limit is adopted is thus:

$$
\begin{aligned}
\operatorname{Pr}(\text { Adoption }) & =\operatorname{Pr}\left(\mathrm{V}_{\mathrm{i}}>\mathrm{V}_{\mathrm{i}}{ }^{*}\right) \\
& =\operatorname{Pr}\left(\varepsilon_{\mathrm{i}}-\varepsilon_{\mathrm{i}}{ }^{\prime}<\alpha-\alpha^{\prime}+\beta \mathrm{Z}_{\mathrm{i}}-\beta^{\prime} \mathrm{X}_{\mathrm{i}}\right) .
\end{aligned}
$$

It is apparent that the average value of $\mathrm{V}$ amongst adopters, $\mathrm{E}(\mathrm{V} \mid$ Adoption $)=$ $\mathrm{E}\left(\mathrm{V} \mid \mathrm{V}>\mathrm{V}^{*}\right)$, must be at least as great as $\mathrm{E}\left(\mathrm{V}^{*}\right)$, the unconditional average value of a statistical life among both adopters and non-adopters. Thus, the measured average value of time costs saved per fatality from the adoption of an increased speed limit is generally greater than the mean value of a statistical life and provides an upper bound on that quantity. More generally, because the left hand side of equation (6) is only observed for adopters, estimation of the parameters of equation (6) may suffer from selection bias.

To make further progress in estimation, we assume that $\varepsilon_{\mathrm{i}}$ and $\varepsilon_{\mathrm{i}}$ ' are joint normally distributed, so that (8) can be estimated by the probit function:

$$
\operatorname{Pr}(\text { Adoption })=F\left[\left(\alpha-\alpha^{\prime}+\beta Z_{i}-\beta^{\prime} X_{i}\right) / \sigma\right],
$$

where $\sigma=\sigma_{\varepsilon}-\varepsilon^{\prime}$ is $\left(\operatorname{var}\left(\varepsilon-\varepsilon^{\prime}\right)\right)^{1 / 2}$ and $\mathrm{F}[\bullet]$ is the cumulative unit normal distribution. It is apparent that even with this functional form assumption, it is only possible to obtain estimates of 
$\left(\alpha-\alpha^{\prime}\right) / \sigma, \beta / \sigma, \beta^{\prime} / \sigma$; the separate parameters in equations (6) and (7) cannot be identified from this probit function alone.

However, since $\mathrm{V}_{\mathrm{i}}$ is observable, it is possible to estimate (6) by the usual selection corrected regression methods (Heckman 1979). In particular,

$$
\mathrm{E}\left(\mathrm{V}_{\mathrm{i}} \mid \text { adoption }\right)=\alpha+\beta \mathrm{Z}_{\mathrm{i}}+\rho \sigma_{\varepsilon} \lambda_{\mathrm{i}},
$$

where $\rho$ is the correlation between $\varepsilon$ and $\varepsilon^{\prime}, \lambda_{\mathrm{i}}=\lambda\left(\mathrm{X}_{\mathrm{i}}, \mathrm{Z}_{\mathrm{i}}\right)=\mathrm{f}\left(\mu^{\prime} \mathrm{W}_{\mathrm{i}}\right) / \mathrm{F}\left(\mu^{\prime} \mathrm{W}_{\mathrm{i}}\right)$, and $\mu^{\prime}$ consists of the vector $\left[\alpha-\alpha^{\prime}, \beta,-\beta^{\prime}\right]^{\prime}$ and $\mathrm{W}_{\mathrm{i}}$ the vector $\left[1, \mathrm{X}_{\mathrm{i}}, \mathrm{Z}_{\mathrm{i}}\right]$. It is apparent that from estimates of (9) and (10) it is possible to obtain estimates of $\alpha^{\prime}$ and $\beta^{\prime}$. These parameters can then be used to derive an estimate of $\mathrm{V}^{*}$, the mean value of a statistical life from (7).

\section{Speed Limit Legislation and a New Approach to Estimating the VSL}

\section{A. A Brief History of Speed Limits}

The first laws imposing restrictive speed limits on motor vehicles were passed in 1901 in Connecticut. With the exception of a Second World War emergency limit of $35 \mathrm{mph}$, the setting of speed limits remained the responsibility of the state and local governments until 1974. In that year Congress enacted the Emergency Highway Energy Conservation Act in response to the perceived "energy crisis." This bill, intended as a fuel conservation measure, required, among other things, a national maximum speed limit of $55 \mathrm{mph}$. This new national speed limit was lower than the existing maximum daytime speed limit in all 50 states.

By 1976 the Federal Highway Administration began to enforce compliance with the national speed limit. Each state was required to measure compliance with the federal limit. States that did not enforce $50 \%$ compliance with the limit were penalized by a $10 \%$ reduction in federal highway funding. By 1987 dissatisfaction with the federally imposed (and enforced) national maximum speed limit led Congress to modify the law to permit states to set speed limits of $65 \mathrm{mph}$ on rural interstate highways only. It seems likely that this dissatisfaction reflected the political important driver's inability to optimally balance travel times and fatality rates.

Even with the end of the concern for fuel conservation, the national maximum speed limit was retained in some form until repeal in 1995. Despite opposition, especially from Western 
states, much of the support for national speed limits may have resulted from the unintended impact that this law appeared to have on motor vehicle fatalities. Figure 1 shows the history of fatalities per vehicle mile traveled (vmt) from 1966-93. It is apparent that fatalities per mile traveled have been declining during this entire period, but the decline of 15 percent (nearly 10,000 fatalities) immediately following passage of the 1974 Emergency Highway Energy Conservation Act is the largest ever recorded in a single year and it was widely remarked upon at the time.

Before proceeding, some clarification of the legislative history may be necessary. In 1995 Congress eliminated entirely the federal regulation of speed limits. By the end of 1997 only three states maintained a $55 \mathrm{mph}$ speed limit on rural interstates: 20 states had rural interstate speed limits of $65 \mathrm{mph}, 16$ were at $70 \mathrm{mph}, 10$ at $75 \mathrm{mph}$, and Montana had no daytime speed limit, returning to its policy in 1973. Uniform and reliable data on this later period is unavailable at this, and hence we do not examine these further changes in speed limits.

B. Using the 1987 Institutional Change to Estimate the VSL

By the end of 1987, 38 states raised the maximum speed limit on their rural interstates and three more joined in 1988. Three states (including Washington D.C.) had no rural interstate highways on which to adjust speed limits, and a final seven states maintained a $55 \mathrm{mph}$ speed limit on all road systems into the 1990s. ${ }^{7}$ Figure 2 graphically displays the location of the states that retained the $55 \mathrm{mph}$ speed limit on rural interstates in the period following 1987. It is apparent that these states are clustered closely together in the more densely populated and wealthy northeast section of the U.S.

We use this institutional change to study the trade off between the value of time saved and risk. We compare changes in speeds and fatalities on rural interstates across states that did and did not adopt the $65 \mathrm{mph}$ limit. In view of the geographic clustering documented in Figure 2 , it is possible that such comparisons would capture effects that were a result of geography only.

\footnotetext{
${ }^{7}$ The seven states that maintained the $55 \mathrm{mph}$ speed limit on rural interstates were: Connecticut, Maryland, Massachusetts, New Jersey, New York, Pennsylvania, and Rhode Island. Three states (Delaware, the District of Columbia, and Hawaii) did not have roads classified as rural interstates throughout this period. The remaining 41 states adopted the $65 \mathrm{mph}$ limit. Although Alaska is in this latter category, it will be ignored in the subsequent analysis because its rural interstates are not comparable to those in other states.
} 
However, because speed limits were permitted to increase only on rural interstates, we also make comparisons within states between the changes on rural interstates and other highways.

There is considerable anecdotal evidence that legislators had plenty of evidence with which to assess the consequences of a change in the speed limit on fatality rates and speeds. First, it was well understood that speed can increase the incidence of accidents by reducing reaction times and that it can increase the severity of crashes because of the physical relationship between mass and speed to energy. Second, the National Research Council provided a review of the effects of the national maximum speed limit in 1984. The report concludes that the $55 \mathrm{mph}$ speed limit was responsible for 3,000 to 5,000 fewer traffic fatalities annually and a sharp decrease in mean speeds on rural interstates (NRC 1984).

Third, state governments also had access to more than a dozen studies of individual state's experiences with speed limits and roughly 10 studies from foreign countries. All of these studies were completed by the mid-1980s, and their estimates of the impacts of speed limits were similar to those produced by the NRC (NRC 1984). Consequently, it seems reasonable to assume that legislators were aware of the trade-offs that they were choosing for their constituents.

The more difficult question is whose preferences determine state government's decisions about speed limits. Our approach assumes that the decisions reflect the median voter's/driver's marginal willingness to trade-off wealth for an increase in the probability of death. Since drivers are both the recipients of the benefits (in reduced driving times) and the costs (an increased fatality risk) this seems plausible. It is possible, of course, that this is not the case. For example, the adoption decision could be captured by a particular industry (e.g., trucking or insurance). This issue cannot be resolved definitively, but the results from the estimation of equation (9) for the probability of adoption reported below do support the hypothesis that the adoption decision is more likely to be made when it is in the interests of the median voter's/driver's preferences.

\section{Data Sources and Description}

\section{A. Data Collection}

Our data on vehicle miles traveled (vmt), fatal accidents, and vehicle speeds come from several sources and reflect considerable effort. Vehicle miles traveled are readily available by 
state and road type from the Federal Highway Administration's Highway Statistics. ${ }^{8}$ These data are collected by taking annual average traffic counts on segments of highways between two entry and/or exit points and multiplying the traffic counts by the length of the highway segments.

Fatalities are available from the Fatal Accident Reporting System, which provides a census of all fatal vehicle crashes in the United States. This reporting system is maintained by the National Highway Traffic Safety Administration and is based on information obtained from state agencies on all accidents involving motor vehicles traveling on public highways that result in the death of one or more person. ${ }^{9}$

Prior to 1981 speeds were monitored by radar. Since that time speed monitoring has been done primarily with wire loops embedded in highway pavement. Loop monitors are difficult to detect, are not used for enforcement, provide better nighttime speed monitoring, and are generally more consistent across locations than radar monitors. We therefore confine our analysis of speeds (and fatalities) to the period since 1981.

Collecting data on travel speeds is considerably more difficult. From 1976 through 1994 the Federal Highway Administration required states to monitor speeds on highways that were posted at $55 \mathrm{mph}$. However, because the provisions requiring the report of speeds pertained only to highways posted at $55 \mathrm{mph}$, many states that increased speed limits on rural interstates discontinued collection of speed data on these roads in 1987.

Some of the $65 \mathrm{mph}$ adopting states did continue to collect speed data after 1987 but did not report them to the federal government. We contacted all state departments of transportation and asked for whatever data existed on rural interstate speeds. Twenty-one of the forty-one states that increased rural interstate speed limits in 1987 and 1988 provided the necessary data, and it is these data that provide the basis for our analysis. ${ }^{10}$ The other states continued to collect speed data in accordance with federal regulations.

\footnotetext{
${ }^{8}$ Highway Statistics, Table VM-2, Federal Highway Administration, various issues.

${ }^{9}$ Bureau of Transportation Statistics, Traffic Safety CD-ROM: 1996, Fatal Accident Reporting System: 1975-1994, U.S. Department of Transportation.

${ }^{10}$ The 21 states that adopted the $65 \mathrm{mph}$ speed limit and provided post-1987 speed data are: Arizona, Arkansas, California, Colorado, Idaho, Illinois, Indiana, Iowa, Kansas, Kentucky, Michigan, Mississippi, Nevada, North Carolina, Ohio, Oregon, South Carolina, South Dakota, Tennessee, Wisconsin, and Wyoming.
} 
Figure 2 displays the geographic location of the 21 states that increased their rural interstate speed limits in 1987 and for which we have been able to obtain data on the speeds actually traveled before and after 1987. It is apparent that the states for which we do have data are widely dispersed across the U.S. Nevertheless, we suspect that the states for which data are not available may have been those that were most anxious to eliminate speed enforcement and reporting requirements. This suggests that the observed speed increases in the states that we can monitor may be smaller than what occurred in the states that we couldn't monitor. Unless the relationship between fatalities and speeds is different in states that we can and cannot monitor, however, this should not affect our empirical analysis.

\section{B. Summary Statistics}

Table 1 provides some of the basic descriptive statistics for our data. Column (1) reports summary information for the 21 states that adopted the $65 \mathrm{mph}$ speed limit on rural interstates and column (2) contains the data from the 7 states that retained the $55 \mathrm{mph}$ speed. Column (3) contains the available information for the 19 states that adopted the higher limit but did not provide us with speed data.

The first panel reports the mean of fatalities, fatality rates, and speeds for three categories of roads and of fatalities and fatality rates across all roads from the years 1982-93. The fatality rate and speed entries are calculated as the weighted mean, where the weight is vehicle miles of travel. The three road categories are rural interstates, rural arterials, and urban interstates. These latter two roads are chosen, because they generally have speed limits of $55 \mathrm{mph}$ and design features that closely resemble those of rural interstates. ${ }^{11}$ It is appealing to have similar roads within adopting states, because they provide better comparisons within adopting states.

A few regularities emerge from this panel. First the fatality rate, which is measured as the number of fatalities per 100 million vehicle miles of travel, is greater in adopting states than in non-adopting ones across the three roadtypes and statewide. Second, average speeds are highest on rural interstates although they are similar on the three roadtypes. Third, rural and

${ }^{11}$ Both rural and urban interstate roads have multiple lanes, with traffic separated by direction and controlled access. Rural arterials generally have one lane in each direction, but they have wide lanes and shoulder lanes. Access to them is less controlled than to interstates, but more than to any other type of road. See National Research Council (1984). 
urban interstates are substantially safer than rural arterials and than the statewide averages. Fourth, the statewide totals indicate that fatalities on rural interstates comprise a small fraction of total fatalities. Within the states in our sample, these roads accounted for $2.5 \%$ and $5.0 \%$ of all traffic fatalities in non-adopting and adopting states, respectively.

The second panel displays mean characteristics of the three sets of states in the years (1982-86) preceding the passage of the federal legislation. Of especial interest are comparisons among the states that adopted the $65 \mathrm{mph}$ speed limit and the states that retained the $55 \mathrm{mph}$ speed limit. It is apparent that the states that adopted the $65 \mathrm{mph}$ speed limit generally had higher fatality rates and speeds. This is true for both sets of $65 \mathrm{mph}$ states. To the extent that level differences predict changes, these differences demonstrate the importance of the availability of intra-state comparisons.

It is also evident that on average adopting states had lower wage rates and lower traffic densities in 1986. It is noteworthy that wage rates and traffic densities are virtually identical in the two sets of adopting states in columns (1) and (3). Overall, these data suggest that traffic densities and wage rates may be related to the probability that a state will adopt the $65 \mathrm{mph}$ speed limit, and we explore this possibility in more detail below.

\section{Unadjusted Estimates of the Effects of the $65 \mathrm{mph}$ Speed Limit}

Figure 3 disaggregates the fatality rate data from the first panel of Table 1. It presents annual mean fatality rates on rural interstates from 1982-1993 for states that adopted (the solid line) the $65 \mathrm{mph}$ speed limit and states (the dotted line) that retained the $55 \mathrm{mph}$ limit for which speed data is also available. ${ }^{12}$ The figure confirms that prior to 1987 fatality rates were higher on rural interstates in adopting states, and generally had declined in these years in both sets of states. The year-to-year variability in fatality rates is also evident and cautions against inferences based on a few years. It is evident that after the higher speed limit was introduced, fatality rates in the $55 \mathrm{mph}$ states continued their downward trend, while fatality rates in the adopting states

12 The annual mean fatality rates are calculated as the weighted mean in adopting and nonadopting states, respectively, where the weight is vehicle miles of travel. An unweighted version of this figure leads to the same qualitative conclusions. 
remained relatively constant. The figure suggests that the $65 \mathrm{mph}$ speed limit is associated with a substantial relative increase in fatality rates.

Figure 4 provides an analogous depiction of trends in annual mean speed in the two sets of states. Prior to 1987 average speeds were approximately equal in the adopting and nonadopting states, although they were trending up at a modestly greater rate among adopters. The most striking feature of the figure is the upward mean shift in average speeds that is immediately visible in 1987. ${ }^{13}$ This mean shift cannot be explained by a continuation of the pre-existing trends. Since average speeds were considerably higher than the permitted $55 \mathrm{mph}$ when the new limit was adopted, it is not surprising that the increase in vehicular speeds was considerably less than the $10 \mathrm{mph}$ that some might have expected. Moreover, traffic density may also have limited the increase in speeds

A simple analysis of the impact of adopting the $65 \mathrm{mph}$ speed limit on rural interstates is contained in the top panel of Table 2A. Columns (1) and (2) report mean fatality rates and speeds from 1982-86 ("pre-period") and 1988-93 ("post-period") and the change between these two periods in adopting and non-adopting states respectively. Column (3) contains the difference between the entries within each row for the two sets of states. Consequently, the entries in column (3) of the "Change" sub-panel are the unadjusted difference in differences (DD) estimates of the effect of the $65 \mathrm{mph}$ speed limit on fatality rates and speeds.

The "Change" sub-panel documents that fatality rates declined by 0.041 and 0.226 on rural interstates in adopting and non-adopting states on rural interstates, respectively. Speeds increased in both adopting and non-adopting states, but the increase was almost $150 \%$ larger in adopting states. Thus, the unadjusted DD estimators suggest that the adoption of the $65 \mathrm{mph}$ speed limit increased fatality rates by 0.185 and speeds by $2.8 \mathrm{mph}$ on rural interstates. ${ }^{14}$

\footnotetext{
${ }^{13}$ In Figure 3 the relative increase in fatality rates is not evident until 1988, but in Figure 4 the increase in speeds is observable in 1987. This difference is because most states initially applied the $65 \mathrm{mph}$ limit during the summer of 1987 and speed data is collected on the calendar year, while fatality data is based on the federal fiscal year that ends on September 30.

${ }^{14}$ Lave (1997) argues that the $65 \mathrm{mph}$ speed limit induced an increase in fatalities on rural interstates and a decrease on other roads so that statewide the $65 \mathrm{mph}$ speed limit did not increase fatalities. Greenstone (2002) reexamines this hypothesis and is unable to find evidence that the $65 \mathrm{mph}$ speed limit caused a decrease in fatality rates on other roads.
} 
The same analysis applied to the data on urban interstate and rural arterial roads is contained in the bottom two panels of Table $2 \mathrm{~A}$. These data indicate that fatality rates decreased modestly more in adopting states than non-adopting ones on both categories of roads. ${ }^{15}$ If this relative decline is due to a state-specific factor, then these roads should be used as an intra-state comparison. It is evident that controlling for this decline will increases the magnitude of the estimated effect of the $65 \mathrm{mph}$ limit on fatalities. The subsequent analysis presents estimates that do and do not use these roads as controls.

There is no relative pattern in the speed data as average speeds increased at about the same rate in adopting and non-adopting states on these roadtypes. Interestingly, the speed data contradict the popular "spillover" hypothesis that higher speed limits on one road cause drivers to increase their driving speed on all roads.

Table $2 \mathrm{~B}$ presents two different methods to calculate unadjusted DD estimators. The column (1) entries are the unadjusted DD estimates from Table 2A, normalized by the pre-period level in adopting states. In the case of rural interstates, they indicate that the adoption of the higher limit is associated with increases of $13.0 \%$ in the fatality rate and $4.7 \%$ in speed. The changes in fatality rates and speed are $-5.9 \%$ and $-0.9 \%$ on urban interstates and $-3.2 \%$ and $0.9 \%$ on rural arterials, respectively.

Although calculations such as those in column (1) are common, the resulting estimate is sensitive to the choice of denominator when there are pre-period differences in the levels. For example, the increase in the fatality rate on rural interstates is approximately $50 \%$ larger when the raw DD estimates are normalized by the pre-period level in non-adopting states. This is because the pre-period fatality rate is roughly 50\% higher in adopting states. Since the preperiod speeds on rural interstates are approximately equal, this issue does not apply to the column (1) speed effect.

15 The DD estimators of the effects of the $65 \mathrm{mph}$ speed limit are generally insensitive to weighting. The principal exception is the effect on urban interstate fatality rates. In the unweighted case, the fatality rate declines by .203 more in adopting states. Greenstone (2000) found a similar relative decline on non-interstate roads in urban areas, which suggests that there is an unobserved factor (e.g., an improvement in the safety of the fleet of cars) that caused the larger declines on all urban roads in adopting states. 
Column (2) reports the results of the application of the DD estimator applied to the $\ln$ transformation of the raw, state by roadtype by year data. The ln difference approach is the only measure of relative change that is symmetric, additive and normed (Tornqvist, Vartia, and Vartia 1985). In contrast to the column (1) estimates, these estimates are independent of the units of measurement (and differences in the pre-period levels). These estimates of the effects of the 65 mph limit on rural interstates are increases of 0.311 and $0.045 \ln$ points for the fatality rate and speed, respectively. The estimated changes on urban interstates are -0.063 and -0.009 ln points and 0.005 and 0.008 on rural arterials.

In general, the column (1) and (2) entries are approximately equal. The most glaring exception is the case of the fatality rate on rural interstates, where the difference in the estimators is due to the differences in the pre-period levels. ${ }^{16}$ This is troubling because our estimate of the trade-off between the monetary value of time and fatalities is proportional to changes in the fatality effect. Consequently, functional form assumptions are more important than we would like. We focus on the results that use the $\ln$ transformation, because this method is independent of the pre-period differences. But, the subsequent analysis also reports results when the fatality rates and speed are untransformed.

\section{Econometric Framework}

This section discusses the econometric models used to estimate how individual's trade-off time spent traveling against the probability of a fatality. The equation of interest is:

$$
\ln (\text { Hours of Travel })_{\text {srt }}=\beta \ln (\mathrm{vmt})_{\mathrm{srt}}+\theta \ln (\text { Fatalities })_{\mathrm{srt}}+\mathrm{v}_{\mathrm{srt}},
$$

where $v_{\text {srt }}=\alpha_{\text {sr }}+\eta_{\mathrm{rt}}+\mu_{\mathrm{st}}+v_{\mathrm{srt}}$. Here, $\mathrm{s}$ references state, $\mathrm{r}$ indicates roadtype, and $\mathrm{t}$ indexes year. The dependent variable is the natural logarithm of hours of travel (that is, the reciprocal of the average speed multiplied by vmt) and $\ln (\mathrm{vmt})_{\text {srt }}$, the natural logarithm of vehicle miles of travel, is a control. Thus the parameter of interest, $\theta$, measures the elasticity of time with respect to fatalities, holding constant vmt. ${ }^{16}$ Differences in the pre-period means is also relevant for the calculation of the fatality effect on
rural arterials where the mean fatality rate was $18 \%$ greater in adopting states from $1982-86$. 
As the specification of the error term indicates, there are a number of potential sources of bias. When the sample is limited to a single roadtype (e.g., rural interstates), it is possible to include unrestricted state-roadtype $\left(\alpha_{\mathrm{sr}}\right)$ and roadtype-year $\left(\eta_{\mathrm{rt}}\right)$ effects. We would like to be able to include covariates (e.g., characteristics of the drivers and their cars) at the state-roadtype-year level, but to the best of our knowledge such data is not collected. As an alternative, we can nonparametrically control for all state-year $\left(\mu_{\mathrm{st}}\right)$ factors when the sample includes multiple roadtypes. Thus in the multiple roadtype samples, the estimated elasticity is robust to permanent factors specific to these state-road combinations (e.g., the quality of the road or the average number of days in a year with unsafe driving conditions due to bad weather), transitory factors common to a roadtype (e.g., federal expenditures to improve rural interstates), and transitory factors common to roadtypes within a state (e.g., state-level economic conditions or a change in a drunk driving laws). ${ }^{17}$ However, it is not robust to time varying state-roadtype determinants of fatalities.

We estimated equation (11) by ordinary least squares, separately on data from rural interstates, urban interstates, and rural arterials. The specification includes state-roadtype and roadtype-year effects. The estimated elasticities (standard errors) from these regressions are $-0.003(.007), 0.006(.005)$, and $0.005(.007)$, respectively. The estimated elasticity is nearly identical when the sample is expanded to include all three roadtypes and the specification includes state by year effects.

These results indicate that in ordinary cross-section regression speeds and fatalities are virtually uncorrelated. Although this may seem puzzling at first, it is not very surprising. After all, people will choose to travel more slowly in order to reduce the likelihood of a fatality when a road is unsafe (e.g., due to poor weather). ${ }^{18}$ This illustrates the difficulty of making causal inferences when there is no exogenous variability in the data. Overall, these results are

\footnotetext{
${ }^{17}$ For example, Keeler (1994), Ruhm (1996), and Dee (1999) show that state-level alcohol taxes and minimum age drinking laws may influence alcohol consumption and consequently traffic fatalities.

18 The absence of variation that is unrelated to unobserved factors may explain why previous research has been unable to establish a systematic relationship between speed and fatalities. See Lave (1985), Levy and Asch (1989), Fowles and Loeb (1989), Snyder (1989), and Lave (1989).
} 
consistent with the possibility that the estimated $\theta$ is biased upwards due to individuals' compensatory behavior.

One solution to this identification problem is to find a variable that causes changes in speed but doesn't affect fatalities, except through speed. A plausible instrument is whether the $65 \mathrm{mph}$ speed limit was in force. In this case, the instrumental variables estimate of the elasticity of time with respect to fatalities is a simple function of two reduced-form relations, the effects of the 65 mph speed limit on Fatalities and Hours of Travel:

(12a) $\ln (\text { Fatalities })_{\text {srt }}=\lambda_{\mathrm{F}} \ln (\mathrm{vmt})_{\mathrm{srt}}+\Pi_{\mathrm{F}} 1(65 \mathrm{mph} \text { limit in force })_{\mathrm{srt}}+\varepsilon_{\text {srt }}$

(12b) $\ln (\text { Hours of Travel })_{\text {srt }}=\lambda_{\mathrm{H}} \ln (\mathrm{vmt})_{\mathrm{srt}}+\Pi_{\mathrm{H}} 1(65 \mathrm{mph} \text { limit in force })_{\text {srt }}+\varepsilon{ }_{\text {srt }}$,

where $\theta_{\mathrm{IV}}=\Pi_{\mathrm{H}} / \Pi_{\mathrm{F}}{ }^{19}$ The indicator variable $1(65 \mathrm{mph} \text { limit in force })_{\text {srt }}$ is equal to 1 if the observation is from a road where $65 \mathrm{mph}$ is the posted speed limit. ${ }^{20}$ The error terms are specified identically to $v_{\text {srt }}$ so the estimation of these equations can include the same set of fixed effects.

Two sufficient conditions for the IV estimator $\left(\theta_{\mathrm{IV}}\right)$ to provide a consistent estimate of the elasticity of time with respect to fatalities are $\Pi_{\mathrm{F}} \neq 0$ and $\mathrm{E}\left[\varepsilon_{\mathrm{srt}} \mathrm{v}_{\mathrm{srt},}\right]=0$. From Tables $2 \mathrm{~A}$ and $2 \mathrm{~B}$ and Figure 3, it is evident that the first condition holds. The second condition requires that unobserved determinants of speed are orthogonal to a state's decision to raise speed limits in 1987, conditional on the roadtype-year, state-roadtype and state-year fixed effects. This latter condition cannot be tested.

\section{Estimates of V, the Monetary Value of Time Saved per Marginal Fatality}

This section uses the econometric framework outlined above to estimate three causal relationships: the effect of the $65 \mathrm{mph}$ speed limit on fatalities, holding constant vmt; the effect of the $65 \mathrm{mph}$ speed limit on hours of travel, holding constant vmt; and the time saved per

${ }^{19}$ We used the Box-Cox method to find the transformation of y (i.e., the dependent variables) in the reduced-form equations so that $\mathrm{y}^{\lambda}$ is approximately normally distributed. In the case of equation (12a), the estimate of $\lambda$ is .5346 with a $95 \%$ confidence interval of $\{.3980, .6810\}$ so both the linear and $\ln$ transformation are rejected. In contrast, the null hypothesis that the $\ln$ transformation is correct cannot be rejected for equation (12b).

${ }^{20}$ This variable is set to 1 in all years after 1987 . For observations from 1987, it is equal to the fraction of the calendar year that the $65 \mathrm{mph}$ limit was in force. 
marginal fatality. The first two "reduced-form" relationships are of interest in their own right as part of an evaluation of the effects of speed limit policies. In the context of our theoretical model, the latter is the key structural relation and provides an upper bound estimate of the value of a statistical life.

A. Estimated Effects of the $65 \mathrm{mph}$ Speed Limit on Fatalities and Speeds

Table 3 provides our basic empirical estimates of the proportionate effect of the adoption of the $65 \mathrm{mph}$ speed limit on fatalities. They are obtained from the fitting of equation (12a). The first column provides estimates of the effect of adoption on fatalities on rural interstates. The first seven rows present estimates from separate regressions where the sample includes data from 1982-86 and one of the years that the higher limit was in force. The estimate in the eighth row is obtained from the full sample and is an average effect across all years. The standard errors of the estimates are in parentheses and are corrected for unspecified heteroskedasticity (White 1980). ${ }^{21}$ The second and third columns of the table provide estimates of the effect of the adoption of the $65 \mathrm{mph}$ speed limit on fatalities on urban interstates and rural arterial roads in the adopting states. These results provide a more formal test of whether there are transitory state level factors that bias the estimates in the first column.

The results in the first column of Table 3 indicate that, in all years when the speed limit was in force for the entire year, fatalities on rural interstates increased by more in the states adopting higher speed limits than in those that did not. ${ }^{22}$ In many cases the individual estimated effects would be judged statistically significant by conventional test criteria. The bottom panel provides an estimate that, because it pools the data for all the years, is considerably more precisely determined than the separate effects estimated by year. This summary result indicates that the adoption of the $65 \mathrm{mph}$ speed limit increased fatalities by about 36\% (measured in $\mathrm{ln}$ points) on rural interstates.

${ }^{21}$ Unless otherwise noted, all the standard errors in the subsequent analysis are corrected for unspecified heteroskedasticity.

${ }^{22}$ Our estimate of the 1990 fatality effect is $.268 \mathrm{ln}$ points, which translates to a $30.7 \%$ increase in fatalities. It is noteworthy that a U.S. Department of Transportation report that evaluated the impact of the $65 \mathrm{mph}$ speed limit on fatalities in 1990 concluded that the fatality toll on rural interstates in adopting states was "30 percent greater than might have been expected" (U.S. Department of Transportation 1992). 
In contrast, the results from urban interstates and rural arterials show little evidence of a systematic change in fatality rates in adopting states after 1986. The estimated annual effects of the increased speed limit on these roads are small and generally would not be judged statistically significant at conventional test levels. Further, there is not a consistent pattern to the signs of the estimates either within a roadtype over time or across the two roadtypes within a year. The overall effects indicate that in adopting states there was a modest relative decline in the fatality rate on urban interstates and a small relative increase on rural arterials that would be judged statistically significant at the $5 \%$ level.

Table 4 provides a precisely parallel analysis of the proportionate effect of the adoption of the $65 \mathrm{mph}$ speed limit on the hours required to travel a mile (that is, the reciprocal of the average speed multiplied by vmt). These are the results of fitting equation (12b). It is striking that all but one of the annual effects is statistically significant at the $5 \%$ level or better. When the data is pooled to include all years, the estimate indicates that the hours required to travel a mile decreased by about $4 \%$ (so speeds increased by about $2.5 \mathrm{mph}$ ) on rural interstates as a result of the speed limit increase. Speeds on urban interstates and rural arterial roads were unaffected by the speed limit change. All of these estimated effects are quite precisely determined in a statistical sense.

Table 5 examines the sensitivity of the estimated effects of increased speed limits on fatalities and speeds, using various alternative specifications. Road types are pooled for the analysis in different ways, as shown by the row labels. In the multiple roadtype samples, the specifications include an indicator for observations from any road in a state-year when the 65 mph limit was in force on that state's rural interstates. However, the reported coefficient is again from an indicator that is equal to 1 for observations from rural interstates in a state-year when 65 mph was the posted limit.

Three different specifications are fit. The specification in column (1) constrains the year indicators to be equal across roadtypes. In column (2), these year indicators are replaced with year-roadtype dummies. The specification in column (3) may be of particular interest, because it includes state-year indicators. 
These estimates provide some sense of the extent to which the quantitative magnitudes of the estimated effects are dependent on the precise specification of the econometric model. In principle, if the quantitative magnitude of the estimates is not affected by the precise specification of the model, then the pooling of the data may result in a more precise estimator. In fact, as the table indicates, the estimated effect of the increased speed limit on fatalities is between $24 \%$ and $42 \%$ and not very sensitive to the precise specification. ${ }^{23}$ Likewise, the estimated effect of the increased speed limit on hours required to travel a mile is between $3.0 \%$ and $4.1 \%$, and it also is not very sensitive to the precise specification. ${ }^{24}$

Thus far the analysis has attempted to obtain the causal effects of the adoption of the 65 mph speed limit on fatalities and travel times. But these estimates are unlikely to be the structural relationships between speed limits and these two outcomes. We suspect that the adoption of the higher speed limit may be accompanied by other changes that are unobservable to us but are intended to affect these outcomes. For example, states may accompany the introduction of higher speed limits with alterations in state trooper behavior that limit the increase in speeds and/or fatalities. Further, the higher speed limit may induce changes in the variance of speed that could have an independent effect on fatality rates (Lave 1985). The available data does not permit an investigation of whether such relationships underlie the above estimates, but such an investigation is unnecessary for our purposes. The important issue is that the adoption of the higher speed limit provided the median voter/driver a trade-off between increased fatalities and reduced travel times, whatever the precise mechanism.

${ }^{23}$ Although speed data is missing for 19 of the 40 adopting states, these states' fatality data is available. Across a variety of specifications, the increase in fatalities on rural interstates in these adopting states was approximately $0.08 \mathrm{ln}$ points higher than in other adopting states. This difference was generally significant at the $10 \%$ level but not when stricter criteria are applied.

${ }^{24} \mathrm{We}$ experimented with adding state-specific and state by roadtype-specific linear time trends to the specifications presented in Table 5. For both fatalities and hours required to travel a mile, the exclusion of a state-specific time trend in columns (1) and (2) is rejected by F-tests. In these specifications, the effect of the $65 \mathrm{mph}$ speed limit is essentially unchanged and its standard error is modestly smaller. Although an F-test rejects the exclusion of state by roadtype linear time trends in columns (1), (2), and (3), this model appears to be "overparameterized." In particular, the standard errors on the indicator for the $65 \mathrm{mph}$ speed limit increase by $50 \%-100 \%$. Nevertheless, the fatality effect remains approximately constant and statistically significant at the $5 \%$ level. The hours point estimate declines by roughly $1 / 2$ and would not be judged significant at conventional levels. 


\section{B. Estimates of the Trade-off Between the Value of Hours Saved and Fatalities}

Tables $6 \mathrm{~A}$ and $6 \mathrm{~B}$ present the results from the estimation of two versions of equation (11). In both cases, an indicator for whether the $65 \mathrm{mph}$ speed limit was in force is used as an instrumental variable for the fatalities variable. The results are obtained from the same 10 combinations of specifications and samples as in Table 5. For each regression, the table reports the IV parameter estimate on the fatality variable, the heteroskedastic consistent standard error in parentheses, and the implied estimate of the monetary value of the time saved per marginal fatality, $\mathrm{V}$, in square brackets.

In Table 6A the dependent variables is $\ln$ (Hours of Travel) and the explanatory variable of interest is $\ln$ (Fatalities). As in equation (11), the specification also includes ln (vmt) as a control. Consequently, the reported parameters are the estimated elasticity of hours required to travel a mile with respect to fatalities. Since the estimated effect is exactly identified, the estimates from a particular specification and sample are the ratio of the estimate in the second panel to the estimate in the first panel from the same sample and specification in Table 5.

Across all of the samples and specifications, the fitting of this equation yields a relatively narrow range of estimates of the elasticity and, in turn, V. The elasticities are between -0.076 and -0.166 , implying that a $10 \%$ increase in fatalities is associated with a $0.76 \%$ to $1.66 \%$ reduction in travel times. These estimates would generally be judged statistically significantly different from zero at conventional test levels.

The estimated V's range from $\$ 1.11$ million to $\$ 2.42$ million. $^{25}$ Our preferred estimate of $\mathrm{V}$ is the weighted average of the estimates from the rural interstate only sample and the column (3) specification with all three roadtypes in the sample, where the weight is the inverse of the standard errors on the elasticities. This summary measure of $\mathrm{V}$ is $\$ 1.54$ million. Other estimates will be higher or lower, depending on the precise parameters used, and some readers may prefer to make different calculations.

25 The estimates of $\mathrm{V}$ are obtained by multiplying the relevant elasticity by the ratio of hours traveled to total fatalities in adopting states from 1982-86 (6.122 billion/5,187) and by the average wage rate in adopting states in 1986 (\$12.33 in 1997\$). 
In Table 6B mean speed is the dependent variable and the explanatory variable of interest is the fatality rate. This equation is weighted by vmt. As discussed in the context of Table $2 \mathrm{~B}$, this approach is not independent of differences in pre-period levels. The sensitivity of the estimates to differences in the pre-period fatality rates is evidenced by the greater variability in the estimates of $\mathrm{V}$ as the sample is changed within each of the columns. In this untransformed case, the "first-stage" fatality effect is generally smaller (recall Table 2B) so the estimates of V are larger on average. ${ }^{26}$ Overall, these estimates of $\mathrm{V}$ range from $\$ 1.39$ million to $\$ 8.91$ million. ${ }^{27}$

\section{Estimates of $V^{*}$, the Value of a Statistical Life}

As noted in the theoretical framework, the estimate of $\mathrm{V}$, the trade-off between the value of hours saved and a marginal fatality provides only an upper bound to the value of a statistical life. In this subsection, we report on our efforts to empirically implement the theoretical model and obtain an estimate of the value of a statistical life, $\mathrm{V}^{*}$.

We begin by obtaining state-by-state estimates of $\mathrm{V}$ for the 21 adopting states that provided speed data. The first six columns of Table 7 present state-by-state estimates and standard errors of the effects of the $65 \mathrm{mph}$ speed limit on fatalities and the time required to travel a mile (cols. 1-4) and the IV elasticity between time saved and fatalities (cols. 5-6). These are obtained from fitting versions of equations (12a), (12b), and (11), respectively, that include the logarithm of vmt interacted with roadtype and state-roadtype, roadtype-year, and state-year fixed effects as controls. The sample for each of these regressions includes observations on rural interstates, urban interstates, and rural arterials from the 7 states that retained the $55 \mathrm{mph}$ limit and the state for which the estimate applies. Column (7) reports the state-specific estimates of $\mathrm{V}^{28}$

\footnotetext{
${ }^{26}$ The "reduced form" results are available from the authors upon request.

${ }^{27}$ In order to obtain these estimates of $\mathrm{V}$, the parameter estimates are converted into elasticities. This is done by multiplying the parameter estimates by the ratio of the mean fatality rate to the mean speed in adopting states (1.423/59.6) during the 1982-86 period. The estimate of $\mathrm{V}$ is then obtained as described in footnote 25 .

28 The state-specific estimates of $\mathrm{V}$ are obtained by multiplying the elasticities by the statespecific ratio of hours traveled to total fatalities and the state-specific mean hourly wage.
} 
Although the parameter estimates from the state-specific regressions are relatively imprecise, they almost all have the expected sign. The estimated effects of the higher limit on fatalities range from -0.039 (Indiana) to 0.656 (South Dakota) ln points, while the speed effects range from 0.033 (Arkansas) to -0.084 (Colorado). 18 of the 21 IV elasticities have a negative sign, but only 3 of them would be judged statistically significant at conventional levels. The estimated value of time saved per marginal fatality (i.e., V) ranges from $-\$ 1.12$ million (Arkansas) to $\$ 9.71$ million (Wisconsin) (1997\$).

Table 8 reports our efforts to use these estimated V's to obtain a structural estimate of $\mathrm{V}^{*}$, the value of a statistical life. The top panel contains estimates from the probit (recall equation (9)) model of the states' likelihood of adopting the higher limit. We assume that the hours saved per fatality will be lower the greater is the traffic density in a state, which implies that in the probit function traffic density will also be negatively related to the probability that a state will adopt the $65 \mathrm{mph}$ speed limit. We also suppose, in accord with some suggestive evidence surveyed by Viscusi (1993), that the value of a statistical life, $V^{*}$ in equation (7), may be positively related to the average wage rate in a state. This implies that the average wage rate will have a negative effect on the probability that a state will adopt the $65 \mathrm{mph}$ speed limit.

The probit function is fit to data on the probability of adoption of the $65 \mathrm{mph}$ speed limit for the full 47 state sample. The results provide strong support for the hypothesis that adoption of the $65 \mathrm{mph}$ speed limit is negatively related to the available time savings. This is suggested by the estimated coefficient on Traffic Density, which is roughly four times its estimated standard error. The estimated effect of the average wage has the sign anticipated and would be judged statistically significant at the $10 \%$ level but not by stricter criteria. These results are consistent with the assumption of our model that states' decisions whether to adopt the higher limit reflect the preferences about benefits and costs of their median/driver voter.

The middle panel presents estimates from modeling the monetary value of the time saved per marginal fatality, V. As specified in equation (6), the control variables are traffic density and the inverse of the Mill's Ratio, calculated using the probit results. These two equations are estimated in a two-step estimation procedure (rather than jointly), because we do not have estimates of $\mathrm{V}$ for 19 of the 40 adopting states but we do want to use data from those states to 
estimate the probit (Heckman 1979). The estimation results from these two equations are used to calculate $\mathrm{V}^{*}$, which is reported in the bottom panel.

The fitting of equation (6) requires the use of estimates of $\mathrm{V}$ as the dependent variable. The precision of these estimates depends on the precision of the estimates of the: IV elasticities, mean wages, mean speeds, and vmt. An examination of the 21 estimated standard errors of the IV elasticities demonstrates one part of the variability in the precision. Although their mean is 0.164, the standard errors associated with the Oregon and Wisconsin elasticities are 0.536 and 0.609 , respectively. Interestingly, these states' estimated V's are the two largest at $\$ 5.41$ and \$9.71 million. It is evident that these two poorly estimated V's are likely to have an important influence on the estimation of equation (6) and that the homoskedasticity assumption is not appealing.

We take a number of approaches to remedy this problem of heteroskedasticity. Column (1) is the result of unweighted least squares estimation, although the standard errors are corrected for unspecified heteroskedasticity (White 1980). Column (2) weights the equation by the reciprocal of the standard errors of the IV elasticities and corrects the standard errors for heteroskedasticity. Column (3) reports median regression results. And, column (4) presents the results from a robust regression routine. This routine begins by excluding outliers, defined as observations with values of Cook's $\mathrm{D}>1$, and then weights observations based on absolute residuals so that large residuals are downweighted. ${ }^{29}$ These estimation details are summarized in the row labels at the bottom of the table.

The results from modeling the state-specific values of $\mathrm{V}$ from Table 7 are mixed. The sign of the parameter on the estimated inverse Mill's Ratio is positive in 3 of the 4 specifications.

29 After the oulier observations are excluded, the routine obtains optimal weights for the remaining observations in an iterative process. This process begins with the estimation of the linear regression on the restricted sample and the calculation of the estimated residuals from this regression. These residuals are used to obtain weights so that observations with large absolute residuals are downweighted. The regression is then fitted again using these weights and the residuals from this new regression are used to derive a new set of weights. This iterative procedure continues until the change in weights is below 0.01. Huber weights (Huber 1964) are used until convergence is achieved and then biweights (Beaton and Tukey 1974) are used until convergence is achieved with them. Street, Carroll, and Ruppert (1998) provide a method to calculate the standard errors. Also see Berk (1990) on robust regression. 
This is not surprising, because it indicates that states with higher values of $\mathrm{V}$ (for unobserved reasons) were more likely to adopt the $65 \mathrm{mph}$ speed limit than would be predicted by the observable determinants of the adoption decision. However, it is apparent that our estimates of this equation are poorly determined. No doubt this is, in part, a result of the very imprecise estimates of $\mathrm{V}$ for individual states that make up the observations.

Nevertheless, the bottom panel of Table 8 concludes our exercise and lists the estimates of the value of a statistical life associated with each of the four specifications. These estimates are calculated at the mean of the 1986 mean hourly wages across adopting states. In square brackets below the estimated $\mathrm{V}^{*}$, we list the parameter estimate from the constant in a regression of the V's on only a constant. They are presented in order to allow for comparisons of our estimates of $\mathrm{V}^{*}$ to the mean and median of the V's from the different procedures. The estimation details in the row labels apply to this simple regression as well.

The estimates of the value of a statistical life range from $\$ .94$ million to $\$ 1.54$ million (1997\$). The relatively tight range of these estimates is reassuring. In three of the four cases, these estimates of $\mathrm{V}^{*}$ are less than the relevant estimates of the mean and median of the V's as our structural model predicts. However, we have not calculated a sampling error for these estimates of the value of a statistical life, but it would no doubt be very large.

\section{Interpretation}

The above estimates of the value of a statistical life are based on our analyses of fatalities and driving time saved from greater speeds. These estimates have several additional conceptual limitations that deserve note. In general, any underestimation of driving time saved, or overestimation of fatalities incurred, will lead to a downward biased estimate of the value of a statistical life. Likewise, any underestimation or overestimation of the economic value of driving time saved will lead to similar biases in the value of a statistical life.

There are plausible reasons for believing that some further adjustments in the estimates may be useful. First, in our analysis we have assumed that each vehicle contains only one passenger, so that vehicle miles traveled are equivalent to passenger miles traveled. In fact, as indicated in Table 9, the typical US vehicle contains 1.7 passengers. If it could be assumed that 
the value of the time of each of these passengers was the same as the mean wage rate per state, and if it could be assumed that the number of passengers per vehicle was the same in each state, it would be appropriate to simply adjust all our estimates of the value of a statistical life upward by this amount.

There are also reasons to believe that the wage rate may not be wholly appropriate as a measure of the value of the passenger time saved. In particular, the wage rate is only one part of total compensation. As Table 9 indicates, total compensation is typically $22 \%$ greater than the wage rate. If it could be assumed that this additional compensation was variable by hour, then it would be appropriate to adjust our earlier estimates of the value of a statistical life upward accordingly.

On the other hand, there is a long tradition in the literature on the economic valuation of travel time that suggests the wage rate may be an overestimate of the value of travel time saved (Beesley 1973). Some of the most convincing evidence on this issue, however, is Deacon and Sonstelie's (1985) analysis of drivers tolerance of waiting times (to obtain less expensive gasoline), which supports the use of the wage rate as a measure of the value of drivers' time.

At the present time, because of data limitations and the inherent subjectivity that would be added to our estimates, we do not think it is appropriate to simply modify the value of statistical life estimates given above using the adjustment factors in Table 9. With better data, however, this may be appropriate at some further time.

Finally, there now exist many estimates of the value of a statistical life both in the US and for other countries and, in fact, there are several surveys of these estimates, including those by Viscusi (1993, 2000), de Blaeij, et. al. (2000), and Blomquist (2001). As a general rule these studies suggest that average valuations across studies typically fall in the range of $\$ 1.0$ to $\$ 5.0$ million, although individual studies often provide estimates far outside this range. Our estimates virtually all fall within this range and we think they provide fairly strong evidence that the more extreme valuations sometimes reported are likely to be a result of one or more conceptual or econometric problems.

\section{Conclusion}


Although subject to a number of limitations, our estimates of the value of a statistical life fall in the range between $\$ 1$ million and $\$ 10$ million, and our preferred estimates are much closer to the former than the latter. We think these estimates are a particularly credible indication of public attitudes toward the tradeoff between wealth and fatality risk. First, these estimates are based on the exogenously offered opportunity for states to vote an increase in their rural speed limit and thereby save vehicle travel time at the risk of increased fatalities. Second, the nature of the risk/wealth tradeoff poses a relatively simple public choice decision where voters receive both the benefits and suffer the costs, and where agency problems and the resulting distortions are not likely to be strong. Finally, there is evidence the state legislators were aware of the tradeoffs involved and that the states that implicitly were offered better terms (greater hours saved per fatality) were more likely to accept the offer.

Based on these results it appears that measuring the choices that result from exogenous changes in the tradeoff between safety and wealth are the key to providing real progress in estimating the value of a statistical life. As would be expected, where drivers select their speeds and thus their fatality risks in response to road conditions, the simple cross-section correlation between speeds and fatality risks is negligible. On the other hand, both speeds and fatality risks increase in response to an exogenous change in speed limits, providing just the information critical to the credible measurement of the value of a statistical life.

Our results also indicate that there is room for much additional research in the valuation of safety risks. Recent years have seen the demise of all federally mandated speed limits and the evolution of considerable variability within states and across states in traffic safety legislation. In principle, this variability could be used to measure the terms of wealth/risk tradeoffs at different levels of risk, and provide better-informed discussions of public policies toward safety.

\section{References}

Beaton, Albert E. and John W. Tukey. "The Fitting of Power Series, Meaning Polynomials, Illustrated on Band-Spectroscopic Data." Technometrics, 16 (1974): 146-85.

Beesley, M.E. Urban Transport: Studies in Economic Policy. London: Butterworth \& Co., Ltd., 1973.

Berk, Richard A. "A Primer on Robust Regression," in Modern Methods of Data Analysis. John 
Fox and J. Scott Long, eds., Newbury Park, CA: Sage Publications, 1990, 292-324.

Black, Duncan. "On the Rationale of Group Decision Making." Journal of Political Economy 56 (1948): 23-34.

Blomquist, Glenn C. "Self Protection and Averting Behavior, Values of Statistical Lives, and Benefit Cost Analysis of Environmental Policy." Mimeograph, University of Kentucky, November 2001.

Bureau of Transportation Statistics, Traffic Safety CD-ROM: 1996, Fatal Accident Reporting System: 1975-1994, U.S. Department of Transportation.

de Blaeij, Arianne, Raymond J.G.M. Florax, Piet Rietveld, and Erik Verhoef. "The Value of a Statistical Life in Road Safety: A Meta-Analysis." Tinbergen Institute Discussion Paper No. 2000-089/3, 2000.

Deacon, Robert T. and Jon Sonstelie. "Rationing by Waiting and the Value of Time: Results from A Natural Experiment." Journal of Political Economy 94 (1985): 627-47.

Dee, Thomas S. "State Alcohol Policies, Teen Drinking and Traffic Fatalities." Journal of Public Economics 72 (1999): 289-315.

Domencich, Thomas A. and McFadden, Daniel. Urban Travel Demand. Amsterdam: NorthHolland, 1975.

Fowles, Richard and Peter D. Loeb. "Speeding Coordination, and the 55 MPH Limit: Comment." American Economic Review 79 (1989): 916-921.

Ghosh, Debapriya; Dennis Lees and William Seal. "Optimal Motorway Speed and Some Valuations of Time and Life." Manchester School of Economic and Social Studies 43 (1975): 134-143.

Greenstone, Michael. "A Reexamination of the Systemwide Effects of the $65 \mathrm{Mph}$ Speed Limit." Economic Inquiry, 40(2) (2002): 271-8.

Heckman, James J. "Sample Selection Bias as a Specification Error." Econometrica, 47(1) (1979): 153-62.

Hersch, Joni. "Compensating Differentials for Gender-Specific Injury Risks." American Economic Review 88(1998): 598-607.

Highway Statistics, Table VM-2, Federal Highway Administration, various issues.

Huber, Peter J. "Robust Estimation of a Location Parameter." Annals of Mathematical Statistics, 35 (1964): 73-101.

Keeler, Theodore. "Highway Safety, Economic Behavior, and Driving Environment." American Economic Review 84 (1994): 684-693.

Khan, Nisar, Kumares C. Sinha, and Patrick S. McCarthy. "An Analysis of Speed Limit Policies for Indiana." FHWA/IN/JTRP-99/14, Joint Transportation Research Project, Purdue University, West Lafayette, IN, 2000.

Lave, Charles. "Speeding Coordination, and the 55 MPH Limit." American Economic Review 75 (1985): 1159-1164.

Lave, Charles. "Speeding Coordination, and the 55 MPH Limit: Reply." American Economic Review 79 (1989): 926-931.

Lave, Charles and Patrick Elias. "Resource Allocation in Public Policy: the Effects of the 65MPH Speed Limit." Economic Inquiry 35 (1997): 614-620.

Lee, N., and M. Dalvi. "Variations in the Value of Travel Time." Manchester School of Economic and Social Studies 37 (1969): 213 - 236.

Levy, David T. and Peter Asch. "Speeding Coordination, and the 55 MPH Limit: Comment." American Economic Review 79 (1989): 913-915. 
National Research Council (U.S.). Transportation Research Board. Fifty-five, a Decade of Experience. Washington D.C.: National Academy Press, 1984.

Ruhm, Christopher J. "Alcohol Policies and Highway Vehicle Fatalities." Journal of Health Economics 15 (1996): 435-454.

Snyder, Donald. "Speeding Coordination, and the 55 MPH Limit: Comment." American Economic Review 79 (1989): 922-925.

Street, James O., Raymond J. Carroll, and David Ruppert. "A Note on Computing Robust Regression Estimates via Iteratively Weighted Least Squares." The American Statistician, 42 (1988):152-4.

Thaler, Richard, and Rosen, Sherwin. "The Value of Saving a Life: Evidence from the Labor Market," in Household Production and Consumption. Nestor E. Terleckyj, ed., Cambridge, MA: NBER, 1976: 265 - 298.

Tornqvist, Leo, Pentti Vartia, and Yrjo O. Vartia. "How Should Relative Changes Be Measured?" The American Statistician 39(1) (1985): 43-46.

U.S. Department of Transportation. "Effects of the 65 MPH Speed Limit through 1990: A Report to Congress." Washington, DC: National Highway Traffic Safety Administration, 1992.

Viscusi, W. Kip. "The Value of Risks to Life and Health." Journal of Economic Literature 31 (1993): $1912-1946$.

Viscusi, W. Kip. "The Value of Life in Legal Contexts: Survey and Critique." American Law and Economics Review, 2 (2000): 195-222.

Waters II, William G. "Values of Travel Time Savings in Road Transport Project Evaluation," in Proceedings of $7^{\text {th }}$ World Conference on Transport Research, Volume 3: Transport Policy, David Hensher, Jenny King, and Tae Hoon Oum, eds., Oxford, England: Elsevier Science Limited, 1996: 507-522.

White, Halbert. "A Heteroskedasticity-Consistent Covariance Matrix Estimator and A Direct Test for Heteroskedasticity." Econometrica, 48(4) (1980): 817-838 
Table 1: Sample Statistics for States that were Eligible to Raise the Speed Limit on Rural Interstates in 1987

\begin{tabular}{lccc}
\hline \hline & \multicolumn{2}{c}{ States Included in the Analysis } & Excluded States \\
\cline { 2 - 4 } & Adopted 65 Mph & Retained 55 Mph & Adopted 65 Mph \\
\hline Number of States & $(1)$ & $(2)$ & $(3)$ \\
Entire Period (1982-93) & 21 & 7 & 19 \\
Rural Interstates & & & \\
$\quad$ Fatalities & 57.3 & 24.3 & 55.6 \\
Fatality Rate & 1.390 & 0.839 & 1.529 \\
Speed (Mph) & 62.4 & 60.4 & Unavailable \\
Urban Interstates & & & \\
Fatalities & 41.0 & 53.5 & 41.9 \\
Fatality Rate & 0.748 & 0.747 & 0.992 \\
Speed (Mph) & 57.5 & 58.8 & 58.3 \\
Rural Arterials & & & \\
Fatalities & 228.5 & 168.9 & 215.8 \\
Fatality Rate & 3.357 & 2.844 & 3.411 \\
Speed (Mph) & 56.5 & 54.4 & 55.8 \\
Statewide Totals & & & \\
Fatalities & 988.5 & 948.8 & 838.9 \\
Fatality Rate & 2.289 & 1.922 & 2.331 \\
Pre-Period (1982-1986) & & & \\
1986 Hourly Wage (1997\$) & $\$ 12.33$ & $\$ 13.97$ & $\$ 12.33$ \\
1986 Rural Int. Traffic Density & 0.0604 & 0.0929 & 0.0597 \\
Rural Int. Fatality Rate & 1.423 & 0.957 & 1.592 \\
Rural Int. Speed (Mph) & 59.5 & 59.3 & 60.2 \\
\hline \hline
\end{tabular}

Notes: The Fatality Rate is calculated as the number of fatalities per 100 million vehiclemiles of travel. Both the Fatality Rate and Speed entries are calculated as the weighted mean within each of the three categories of states, where the weight is the vehicle miles of travel on the relevant road(s). Traffic Density is vehicle miles of travel per miles of paved road lanes. The mean hourly wage in 1986 is calculated from the 1986 Current Population Survey Outgoing Rotation Group. It is calculated from all workers that report an hourly wage greater than $\$ 2.50$. The survey top-codes the hourly wages of workers that are paid on an hourly basis at $\$ 99.99$. We constructed an hourly wage for workers that are not paid hourly and also top-coded it at \$99.99. The Fatalities, Hourly Wage and Traffic Density entries are the mean across states within each category. See the text and Figure 2 for the identity of the states in each category. 
Table 2A: Mean Fatality Rates and Speeds by Roadtype, Period, and Adopter Status

Adopted 65 Mph Retained 55 Mph Adopters - Non-Adopters

(1)

Rural Interstates (Affected Roadtype)

Pre-Period (1982-1986)

Fatality Rate

Speed (Mph)

1.423

59.6

1.382

64.3

(2)

(3)

Post-Period (1988-1993)

Fatality Rate

Speed (Mph)

Change (Post - Pre Period)

Fatality Rate

$-0.041$

4.7

Speed (Mph)

Urban Interstates (Unaffected Roadtype)

Pre-Period (1982-1986)

Fatality Rate

0.887

Speed (Mph)

56.9

0.662

57.9

$-0.225$

1.0

Speed (Mph)

0.957

59.3

0.731

61.2

$-0.226$

1.9

0.843

57.9

0.670

59.4

$-0.173$

1.5
3.195

53.7

2.511

55.0

0.467

57.2

Speed (Mph)

Change (Post - Pre Period)

Fatality Rate

$-0.807$

1.8
$-0.684$

1.3
0.466

0.3

0.651

3.1

0.185

2.8

0.044

$-1.0$

$-0.008$

$-1.5$

$-0.052$

$-0.5$
Speed (Mph)

s (1) and (2), the Fatality rate and the Speed variables are calculated as the weighted mean across states for each category of road in the Pre-Period and Post-Period panels, where vehicle miles of travel is the weight. The entries in the Change panel are the difference between the Post-Period and Pre-Period means. Column (3) presents the difference of the column (1) and (2) entries for each row. 
Table 2B: Difference in Differences Estimates of $65 \mathrm{Mph}$ Speed Limit on Fatality Rates and Speeds

\begin{tabular}{|c|c|c|}
\hline & $\begin{array}{l}\frac{\text { DD of Levels Normalized by }}{\text { Pre-Period Level in Adopting States }} \\
\text { (1) }\end{array}$ & $\begin{array}{c}\text { DD of Natural Logarithms } \\
\text { (2) }\end{array}$ \\
\hline \multicolumn{3}{|c|}{ Rural Interstates (Affected Roadtype) } \\
\hline Fatality Rate & $13.0 \%$ & 0.311 \\
\hline Speed & $4.7 \%$ & 0.045 \\
\hline \multicolumn{3}{|c|}{ Urban Interstates (Unaffected Roadtype) } \\
\hline Fatality Rate & $-5.9 \%$ & -0.063 \\
\hline Speed & $-0.9 \%$ & -0.009 \\
\hline \multicolumn{3}{|c|}{ Rural Arterials (Unaffected Roadtype) } \\
\hline Fatality Rate & $-3.2 \%$ & 0.005 \\
\hline Speed & $0.9 \%$ & 0.008 \\
\hline
\end{tabular}

See Notes to Tables 1 and 2A. The entries in this table represent two different difference in differences estimates of the effects of the $65 \mathrm{mph}$ speed limit on fatality rates and speeds. The column (1) entries are the raw DD estimates from Table 2A, normalized by the pre-period level in adopting states. The column (2) entries are calculated with the mean of $\ln$ (fatality rate) and $\ln$ (speed) for adopters and nonadopters in the pre and post periods. The entries are equal to the post - pre difference of weighted means among adopters minus the post - pre difference of weighted means among non-adopters, where the weight is vehicle miles of travel. 
Table 3: Proportionate (Log) Effect of the Adoption of the $65 \mathrm{mph}$ Speed Limit on Fatalities Controlling for the Observed Mileage, by Roadtype

\begin{tabular}{|c|c|c|c|}
\hline \multirow[b]{3}{*}{ Sample } & \multirow{2}{*}{$\frac{\text { Affected Roadtype }}{\text { Rural Interstates }}$} & \multicolumn{2}{|c|}{ Unaffected Roadtypes } \\
\hline & & Urban Interstates & Rural Arterials \\
\hline & (1) & (2) & (3) \\
\hline \multicolumn{4}{|l|}{ Annual Effects } \\
\hline \multirow[t]{2}{*}{$1982-6,1987$} & -0.098 & -0.203 & -0.062 \\
\hline & $(.195)$ & $(.174)$ & $(.119)$ \\
\hline \multirow[t]{2}{*}{$1982-6,1988$} & $0.351^{*}$ & $-0.223 *$ & -0.073 \\
\hline & $(.165)$ & $(.111)$ & $(.050)$ \\
\hline \multirow[t]{2}{*}{ 1982-6, 1989} & 0.473 & -0.062 & 0.021 \\
\hline & $(.259)$ & $(.142)$ & $(.071)$ \\
\hline \multirow[t]{2}{*}{$1982-6,1990$} & 0.268 & 0.073 & $0.181 *$ \\
\hline & $(.163)$ & $(.161)$ & $(.090)$ \\
\hline \multirow{2}{*}{$1982-6,1991$} & 0.202 & -0.097 & $0.238 * *$ \\
\hline & $(.123)$ & $(.135)$ & $(.073)$ \\
\hline \multirow[t]{2}{*}{ 1982-6, 1992} & $0.399 * *$ & -0.012 & $0.140 *$ \\
\hline & $(.162)$ & $(.190)$ & $(.087)$ \\
\hline \multirow[t]{2}{*}{$1982-6,1993$} & $0.493 * *$ & -0.059 & 0.113 \\
\hline & $(.179)$ & $(.154)$ & $(.077)$ \\
\hline \multicolumn{4}{|l|}{ Average Effect } \\
\hline \multirow[t]{2}{*}{$1982-1993$} & $0.360 * *$ & -0.056 & $0.082 *$ \\
\hline & $(.091)$ & $(.073)$ & $(.040)$ \\
\hline
\end{tabular}

Notes: The entries are estimated regression coefficients from an indicator for whether the $65 \mathrm{mph}$ speed limit was in force in the state by year in models for the dependent variable of the natural logarithim of the number of fatalities. These models include the $\ln$ of vehicle-miles of travel and state-roadtype and year-roadtype fixed effects. The sample includes the 28 states ( 21 adopted) with rural interstates and for whom speed data are available. The years included in the sample are noted in the row headings. Heteroskedastic consistent standard errors are reported in parentheses. indicates significance at 5\% level; ** indicates significance at $1 \%$ level. 
Table 4: Proportionate (Log) Effect of the Adoption of the $65 \mathrm{mph}$ Speed Limit on Hour Required to Travel the Observed Mileage, by Roadtype

\begin{tabular}{|c|c|c|c|}
\hline Sample & $\begin{array}{c}\frac{\text { Affected Roadtype }}{\text { Rural Interstates }} \\
(1) \\
\end{array}$ & $\frac{\text { Unaffected }}{\frac{\text { Unan Interstates }}{(2)}}$ & $\begin{array}{l}\frac{\text { Rodtypes }}{\text { Rural Arterials }} \\
(3) \\
\end{array}$ \\
\hline$\frac{\text { Annual Effects }}{1982-6,1987}$ & $\begin{array}{c}-0.039 * \\
(.018)\end{array}$ & $\begin{array}{l}-0.014 \\
(.018)\end{array}$ & $\begin{array}{l}-0.047 \\
(.025)\end{array}$ \\
\hline $1982-6,1988$ & $\begin{array}{c}-0.041^{* *} \\
(.009)\end{array}$ & $\begin{array}{l}-0.002 \\
(.011)\end{array}$ & $\begin{array}{l}-0.006 \\
(.007)\end{array}$ \\
\hline $1982-6,1989$ & $\begin{array}{c}-0.038 * \\
(.018)\end{array}$ & $\begin{array}{l}0.004 \\
(.014)\end{array}$ & $\begin{array}{l}0.007 \\
(.013)\end{array}$ \\
\hline $1982-6,1990$ & $\begin{array}{l}-0.025 \\
(.017)\end{array}$ & $\begin{array}{l}-0.011 \\
(.016)\end{array}$ & $\begin{array}{l}0.002 \\
(.013)\end{array}$ \\
\hline $1982-6,1991$ & $\begin{array}{c}-0.043 * * \\
(.017)\end{array}$ & $\begin{array}{l}-0.012 \\
(.015)\end{array}$ & $\begin{array}{l}0.005 \\
(.010)\end{array}$ \\
\hline $1982-6,1992$ & $\begin{array}{c}-0.057 * * \\
(.017)\end{array}$ & $\begin{array}{l}-0.021 \\
(.019)\end{array}$ & $\begin{array}{l}0.003 \\
(.014)\end{array}$ \\
\hline $1982-6,1993$ & $\begin{array}{c}-0.054 * * \\
(.015)\end{array}$ & $\begin{array}{l}-0.024 \\
(.014)\end{array}$ & $\begin{array}{l}0.002 \\
(.016)\end{array}$ \\
\hline$\frac{\text { Average Effect }}{1982-1993}$ & $\begin{array}{c}-0.041 * * \\
(.007) \\
\end{array}$ & $\begin{array}{r}-0.009 \\
(.007) \\
\end{array}$ & $\begin{array}{r}-0.000 \\
(.007) \\
\end{array}$ \\
\hline
\end{tabular}

Notes: The entries are estimated regression coefficients from an indicator for whether the $65 \mathrm{mph}$ speed limit was in force in the state by year in models for the dependent variable of hours required to drive the observed mileage. These models include the $\ln$ of vehicle-miles of travel and state-roadtype and year-roadtype fixed effects. The sample includes the 28 states (21 adopted) with rural interstates and for whom speed data are available. The years included in the sample are noted in the row headings. Heteroskedastic consistent standard errors are reported in parentheses. * indicates significance at 5\% level; ** indicates significance at $1 \%$ level. 
Table 5: Testing the Robustness of the Effect of the $65 \mathrm{Mph}$ Speed Limit on Fatalities and Travel Times

\begin{tabular}{lccc}
\hline \hline Sample & $(1)$ & $(2)$ & $(3)$ \\
\hline \multicolumn{1}{l}{ Dep. Variable: Ln (Fatalities) } & & & \\
Rural Interstates & ------- & $0.360^{* *}$ & ------- \\
Only & & $(.091)$ & \\
Rural Interstates \& & $0.312^{* *}$ & $0.417^{* *}$ & $0.414^{* *}$ \\
Urban Interstates & $(.097)$ & $(.117)$ & $(.130)$ \\
Rural Interstates \& & $0.244^{* *}$ & $0.278^{* *}$ & $0.269^{* *}$ \\
Rural Arterials & $(.070)$ & $(.099)$ & $(.098)$ \\
All Three & $0.280^{* *}$ & $0.349^{* *}$ & $0.337^{* *}$ \\
Roadtypes & $(.073)$ & $(.101)$ & $(.096)$ \\
Dep. Variable: Ln (Hours of Travel) & & \\
Rural Interstates & -------- & $-0.041^{* *}$ & --------- \\
Only & & $(.007)$ & \\
Rural Interstates \& & $-0.030^{* *}$ & $-0.032^{* *}$ & $-0.031^{* *}$ \\
Urban Interstates & $(.007)$ & $(.010)$ & $(.007)$ \\
Rural Interstates \& & $-0.041^{* *}$ & $-0.040^{* *}$ & $-0.033^{* *}$ \\
Rural Arterials & $(.006)$ & $(.010)$ & $(.008)$ \\
All Three & $-0.036^{* *}$ & $-0.036^{* *}$ & $-0.033^{* *}$ \\
& $(.006)$ & $(.009)$ & $(.006)$ \\
Ln (vmt) x Roadtype & Yes & Yes & Yes \\
Year Indicators & Yes & No & No \\
Year-Roadtype Indicators & No & Yes & Yes \\
State-Roadtype Indicators & Yes & Yes & Yes \\
State-Year Indicators & No & No & Yes \\
\hline \hline
\end{tabular}

Notes: The two panels present results from regressions where the dependent variables are the $\ln$ of fatalities and $\ln$ of hours driving, respectively. The entries are the estimated regression coefficients for an indicator that is equal to 1 for observations from rural interstates when the $65 \mathrm{mph}$ speed limit is in force. Road types are pooled for the analysis in different ways, as shown by the row labels. The bottom of the table lists the controls in each of the specifications. Heteroskedastic consistent standard errors are reported in parentheses. * indicates significance at $5 \%$ level; ** indicates significance at $1 \%$ level. 
Table 6A: Estimates of the Monetary Value of the Time Saved per Marginal Fatality Sample

(1)

(2)

(3)

\begin{tabular}{|c|c|c|c|}
\hline \multicolumn{4}{|c|}{ "Functional Form I: Ln Transformation } \\
\hline Rural Interstates & --------- & $-0.113 * *$ & --------- \\
\hline \multirow[t]{2}{*}{ Only } & \multicolumn{3}{|c|}{$(.037)$} \\
\hline & \multicolumn{3}{|c|}{ [\$1.64 million] } \\
\hline Rural Interstates \& & $-0.095 *$ & $-0.076^{*}$ & $-0.076^{* *}$ \\
\hline \multirow[t]{2}{*}{ Urban Interstates } & $(.040)$ & $(.034)$ & $(.031)$ \\
\hline & [\$1.38 million] & [\$1.11 million] & [\$1.11 million] \\
\hline Rural Interstates \& & $-0.166 * *$ & $-0.146^{*}$ & $-0.122 *$ \\
\hline \multirow[t]{2}{*}{ Rural Arterials } & $(.057)$ & $(.066)$ & $(.051)$ \\
\hline & [\$2.42 million] & [\$2.12 million] & [\$1.78 million] \\
\hline \multirow[t]{3}{*}{ All Three } & $-0.128 * *$ & $-0.103 * *$ & $-0.099 * *$ \\
\hline & $(.042)$ & $(.041)$ & $(.034)$ \\
\hline & [\$1.86 million] & [\$1.50 million] & [\$1.44 million] \\
\hline Year Indicators & Yes & No & No \\
\hline Year-Roadtype Indicators & No & Yes & Yes \\
\hline State-Roadtype Indicators & Yes & Yes & Yes \\
\hline State-Year Indicators & No & No & No \\
\hline \multicolumn{4}{|c|}{$\begin{array}{l}\text { Notes: See Notes to Table } 5 \text {. The entries report the results from regressions of } \\
\text { ln (Hours of Travel) on } \ln \text { (Fatalities), where an indicator for whether the } 65 \\
\text { mph speed limit was in force is an instrumental variable for ln (Fatalities). Ln } \\
\text { (vmt) is a control and its effect is allowed to vary by roadtype. The entries are } \\
\text { the parameter estimates and heteroskedastic consistent standard errors (in } \\
\text { parentheses) on ln (Fatalities) and the implied monetary value of the time saved } \\
\text { per marginal fatality, V, [in square brackets]. * indicates significance at } 5 \% \\
\text { level; ** indicates significance at } 1 \% \text { level. }\end{array}$} \\
\hline
\end{tabular}


Table 6B: Estimates of the Monetary Value of the Time Saved per Marginal Fatality Sample

(1)

(2)

(3)

\begin{tabular}{|c|c|c|c|}
\hline \multicolumn{4}{|c|}{ F Functional Form II: Untransformed } \\
\hline Rural Interstates & -------- & $17.03 *$ & --------- \\
\hline \multirow[t]{2}{*}{ Only } & & $(7.67)$ & \\
\hline & & [\$5.92 million] & \\
\hline Rural Interstates \& & $25.64 * *$ & $16.39 *$ & $8.65^{*}$ \\
\hline \multirow[t]{2}{*}{ Urban Interstates } & $(9.42)$ & $(7.46)$ & $(3.84)$ \\
\hline & [\$8.91 million] & [\$5.69 million] & [\$3.00 million] \\
\hline Rural Interstates \& & $4.01 * *$ & 8.25 & $7.88^{*}$ \\
\hline \multirow[t]{2}{*}{ Rural Arterials } & $(0.51)$ & $(4.32)$ & $(3.79)$ \\
\hline & [\$1.39 million] & [\$2.87 million] & [\$2.74 million] \\
\hline \multirow[t]{3}{*}{ All Three } & $6.97 * *$ & $11.98^{*}$ & $8.80 * *$ \\
\hline & $(1.16)$ & $(5.06)$ & $(3.57)$ \\
\hline & [\$2.42 million] & [\$4.16 million] & [\$3.06 million] \\
\hline Year Indicators & Yes & No & No \\
\hline Year-Roadtype Indicators & No & Yes & Yes \\
\hline State-Roadtype Indicators & Yes & Yes & Yes \\
\hline State-Year Indicators & No & No & No \\
\hline
\end{tabular}

Notes: See Notes to Table 5. The entries report the results from regressions of speed on the fatality rate, where an indicator for whether the $65 \mathrm{mph}$ speed limit was in force is an instrumental variable for the fatality rate. The equation is weighted by vmt. The entries are the parameter estimates and heteroskedastic consistent standard errors (in parentheses) on the fatality rate and the implied monetary value of the time saved per marginal fatality, V, [in square brackets]. $*$ indicates significance at $5 \%$ level, $* *$ indicates significance at $1 \%$ level. 
Table 7: State-by-State Estimates of Monetary Value of Time Saved per Marginal Fatality

\begin{tabular}{|c|c|c|c|c|c|c|c|}
\hline & \multicolumn{2}{|c|}{ "Fatality Effect" } & \multicolumn{2}{|c|}{ "Speed Effect" } & \multicolumn{2}{|c|}{ IV Elasticity } & \multirow[b]{2}{*}{$\begin{array}{l}\text { Estimated Value of } \\
\text { Time Saved } \\
\text { per Fatality } \\
\text { Millions of } 1997 \$ \\
(7)\end{array}$} \\
\hline & $\begin{array}{c}\text { Parameter } \\
\text { Estimate } \\
\text { (1) }\end{array}$ & $\begin{array}{c}\text { Standard } \\
\text { Error } \\
(2)\end{array}$ & $\begin{array}{c}\text { Parameter } \\
\text { Estimate } \\
\text { (3) }\end{array}$ & $\begin{array}{c}\text { Standard } \\
\text { Error } \\
\text { (4) }\end{array}$ & $\begin{array}{c}\text { Parameter } \\
\text { Estimate } \\
\text { (5) }\end{array}$ & $\begin{array}{c}\text { Standard } \\
\text { Error } \\
\text { (6) }\end{array}$ & \\
\hline Arizona & 0.229 & (.178) & $-0.054 * *$ & (.017) & -0.239 & $(.215)$ & $\$ \$ 1.92$ \\
\hline Arkansas & 0.348 & $(.250)$ & $0.033 * *$ & $(.010)$ & 0.094 & $(.072)$ & $-\$ 1.12$ \\
\hline California & 0.139 & $(.123)$ & $-0.060 * *$ & $(.012)$ & -0.431 & $(.403)$ & $\$ 4.75$ \\
\hline Colorado & $0.396 *$ & $(.179)$ & $-0.084 * *$ & $(.013)$ & $-0.212 *$ & $(.089)$ & $\$ 2.31$ \\
\hline Idaho & 0.335 & $(.279)$ & $-0.081 * *$ & $(.011)$ & -0.241 & $(.201)$ & $\$ 2.05$ \\
\hline Illinois & $0.310 *$ & $(.155)$ & $-0.040 * *$ & $(.008)$ & -0.128 & $(.076)$ & $\$ 3.19$ \\
\hline Indiana & -0.039 & $(.271)$ & 0.002 & $(.012)$ & 0.045 & $(.497)$ & $-\$ 0.70$ \\
\hline Iowa & $0.505 * *$ & $(.184)$ & $-0.053 * *$ & $(.015)$ & $-0.106^{*}$ & $(.053)$ & $\$ 2.97$ \\
\hline Kansas & 0.377 & $(.234)$ & $-0.042 * *$ & $(.014)$ & -0.113 & $(.077)$ & $\$ 1.96$ \\
\hline Kentucky & $0.461 *$ & $(.214)$ & -0.033 & $(.019)$ & -0.071 & $(.049)$ & $\$ 1.24$ \\
\hline Michigan & $0.591 * *$ & $(.221)$ & -0.019 & $(.015)$ & -0.033 & $(.029)$ & $\$ 0.99$ \\
\hline Mississippi & 0.193 & $(.205)$ & -0.015 & $(.017)$ & -0.079 & $(.120)$ & $\$ 0.76$ \\
\hline Nevada & 0.261 & $(.253)$ & -0.022 & $(.017)$ & -0.082 & $(.098)$ & $\$ 0.49$ \\
\hline North Carolina & $0.612^{*}$ & $(.290)$ & $-0.037 * *$ & $(.012)$ & -0.061 & $(.035)$ & $\$ 1.09$ \\
\hline Ohio & $0.553 *$ & $(.232)$ & 0.007 & $(.015)$ & 0.013 & $(.027)$ & $-\$ 0.47$ \\
\hline Oregon & 0.141 & $(.220)$ & $-0.048 * *$ & $(.013)$ & -0.340 & $(.536)$ & $\$ 5.41$ \\
\hline South Carolina & 0.405 & $(.247)$ & $-0.040 * *$ & $(.014)$ & -0.099 & $(.077)$ & $\$ 1.68$ \\
\hline South Dakota & $0.656^{*}$ & $(.274)$ & $-0.072 * *$ & $(.013)$ & $-0.110^{*}$ & $(.049)$ & $\$ 1.92$ \\
\hline Tennessee & $0.316^{*}$ & $(.147)$ & -0.006 & $(.013)$ & -0.020 & $(.043)$ & $\$ 0.29$ \\
\hline Wisconsin & 0.118 & $(.227)$ & $-0.039 * *$ & $(.014)$ & -0.330 & $(.609)$ & $\$ 9.71$ \\
\hline Wyoming & 0.301 & $(.315)$ & -0.017 & $(.016)$ & -0.055 & $(.088)$ & $\$ 0.50$ \\
\hline
\end{tabular}

Notes: See Notes to Tables 5 and 6A and 6B. The entries in columns (1)-(2), (3)-(4), and (5)-(6) are from fitting equations (12a), (12b), and (11), respectively. The sample for each of these regressions includes observations on rural interstates, urban interstates, and rural arterials from the 7 states that retained the $55 \mathrm{mph}$ limit and the state for which the estimate applies. The controls include the logarithm of vmt interacted with roadtype and state-roadtype, roadtype-year, and state-year fixed effects. Five states (Indiana, Kentucky, Mississippi, Ohio, and Wyoming) had missing speed data for 1 to 3 years during the period when the $65 \mathrm{mph}$ speed limit was in force. In the estimation of the state-specific parameters for these states, the observations from the states that retained the $55 \mathrm{mph}$ limit were dropped in those years. The state-specific IV estimated values of time saved per marginal fatality are calculated by multiplying the IV elasticity (column (5)) by the state-specific ratio of hours traveled to total fatalities and the statespecific mean hourly wage. Heteroskedastic consistent standard errors are reported in parentheses. * indicates significance at 5\% level; ** indicates significance at $1 \%$ level. 
Table 8: Recovering the Value of a Statistical Life, $\mathrm{V}^{*}$

(1)

(2)

(3)

(4)

\begin{tabular}{lcccc}
\hline \hline Probit Estimates for Probability of Adoption & & & & \\
Constant & $8.24^{* *}$ & $8.24^{* *}$ & $8.24^{* *}$ & $8.24^{* *}$ \\
& $(2.87)$ & $(2.87)$ & $(2.87)$ & $(2.87)$ \\
Traffic Density in 1986 & $-32.21^{* *}$ & $-32.21^{* *}$ & $-32.21^{* *}$ & $-32.21^{* *}$ \\
& $(8.00)$ & $(8.00)$ & $(8.00)$ & $(8.00)$ \\
Mean Wage in 1986 & -0.56 & -0.56 & -0.56 & -0.56 \\
& $(0.32)$ & $(0.32)$ & $(0.32)$ & $(0.32)$ \\
Estimates from Value of Time Saved per Fatality $(\mathrm{i} . \mathrm{e} ., \mathrm{V})$ & Equation & & \\
Constant & $2.56^{* *}$ & $2.46^{* *}$ & $2.77^{* *}$ & $2.39^{*}$ \\
& $(0.76)$ & $(0.90)$ & $(0.98)$ & $(1.12)$ \\
Traffic Density in 1986 & -24.52 & -23.39 & -35.74 & -34.94 \\
& $(20.87)$ & $(20.21)$ & $(28.07)$ & $(26.40)$ \\
Inverse of Mill's Ratio & 3.60 & -0.12 & 5.42 & 4.74 \\
& $(2.07)$ & $(2.21)$ & $(5.29)$ & $(2.49)$ \\
Value of a Statistical Life & & & & \\
V* (millions of 1997\$s) & $\$ 1.54$ & $\$ 1.49$ & $\$ 1.29$ & $\$ 0.94$ \\
& {$[\$ 1.95]$} & {$[\$ 1.18]$} & {$[\$ 1.68]$} & {$[\$ 1.48]$} \\
Huber-White Std. Errors in V Equation & Yes & Yes & No & No \\
Bootstrapped Standard Errors in V Equation & No & No & Yes & No \\
Weight V Eq. by Inverse of Elasticity's Std Err & No & Yes & No & No \\
Median Regression & No & No & Yes & No \\
Robust Regression & No & No & No & Yes \\
\hline \hline
\end{tabular}

Notes: The first panel presents estimates and Huber-White standard errors (in parentheses) from the probit equation for the probability that a state adopted the $65 \mathrm{mph}$ speed limit, which is equation (9) in the text. This equation is estimated on the 47 states with rural interstates. The second panel presents estimates from the fitting of the $\mathrm{V}$ equation, which is equation (6) in the text. The inverse of the Mill's ratio is calculated with the results from the probit equation. These equations are estimated in two-steps, because we do not have $\mathrm{V}$ data for 19 of the 40 adopting states but we want to use data from those states in estimating the probit. The row labels at the bottom of the table provide estimation details on the second step. The third panel presents the estimated value of a statistical life, $\mathrm{V}^{*}$. It is calculated with the parameters from the first two panels as described in Section I of the text. In square brackets below the estimated $\mathrm{V}^{*}$, we list the parameter estimate from the constant in a regression of the V's on a constant. The estimation details in the row labels apply to this simple regression as well. * indicates significance at $5 \%$ level; ** indicates significance at $1 \%$ level. 
Table 9: Adjustments to the Estimates of V and $\mathrm{V}^{*}$

Adjust the Value of a Hour for Nonwage Compensation in 1986

$\frac{\begin{array}{c}\text { Adjust Hours Saved for the } \\ \text { Average Number of Car Occupants }\end{array}}{\underline{\text { in } 1986}}$

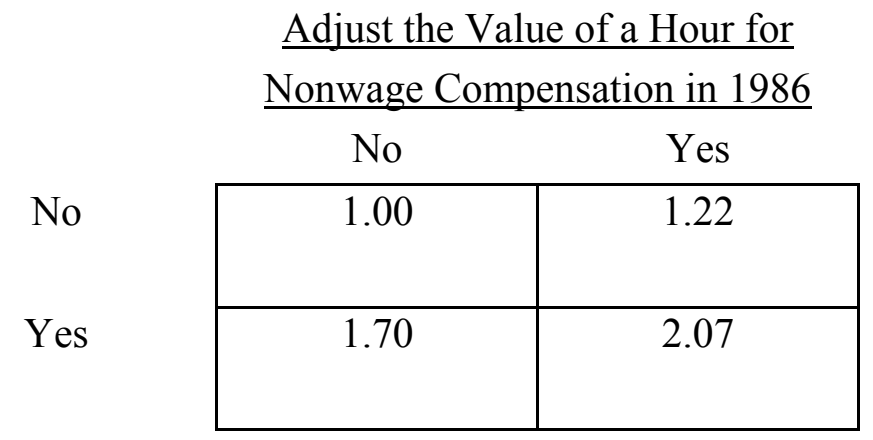

Notes: The estimated number of occupants per vehicle in 1986 is obtained by taking the mean of this variable from the 1983 and 1990 Nationwide Personal Transportation Surveys. These surveys are not representative at the state level, so we cannot calculate state-specific estimates of hours saved that account for the number of occupants per vehicle. The best estimate of nonwage compensation comes from the National Income and Product Accounts (NIPA) of the United States. Total compensation to employees was \$2.571 (in billions) in 1986. "Wage and Salary Accruals" accounted for $\$ 2.114$ and "Supplements to Wages and Salaries" comprised the remaining \$0.456. The Current Population Survey Outgoing Rotation Group measure of wages is similar to the NIPA "Wage and Salary Accruals" category, so we estimate that nonwage compensation was equal to approximately $22 \%$ of wage and salary income in 1986. 
Figure 1: Trend in Driving Fatality Rate on all Roadtypes, 1966-1993

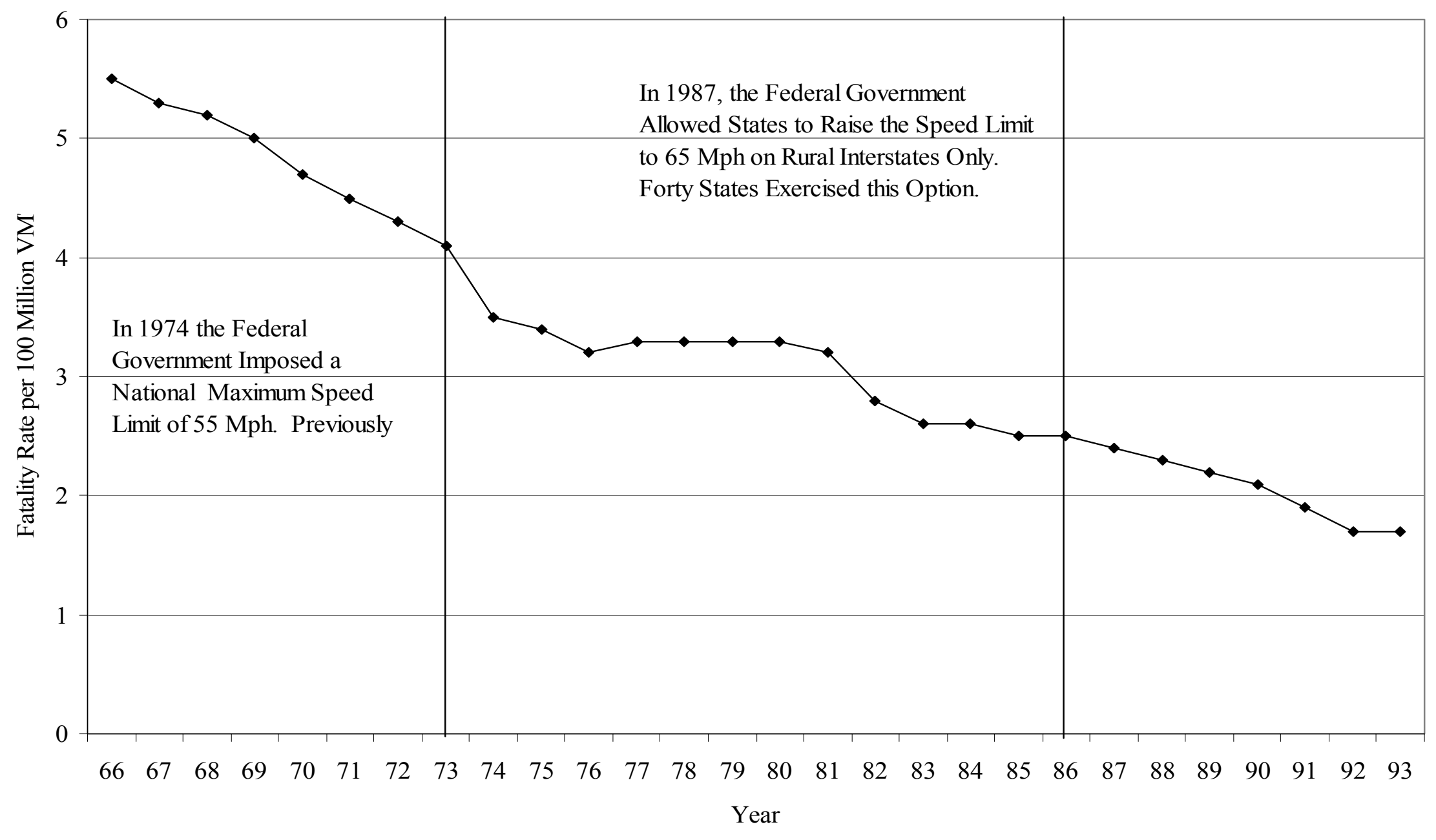

$\multimap$ Fatality Rate per 100 Million VMT 
Figure 2: Adoption Status and Speed Data Availability, by State

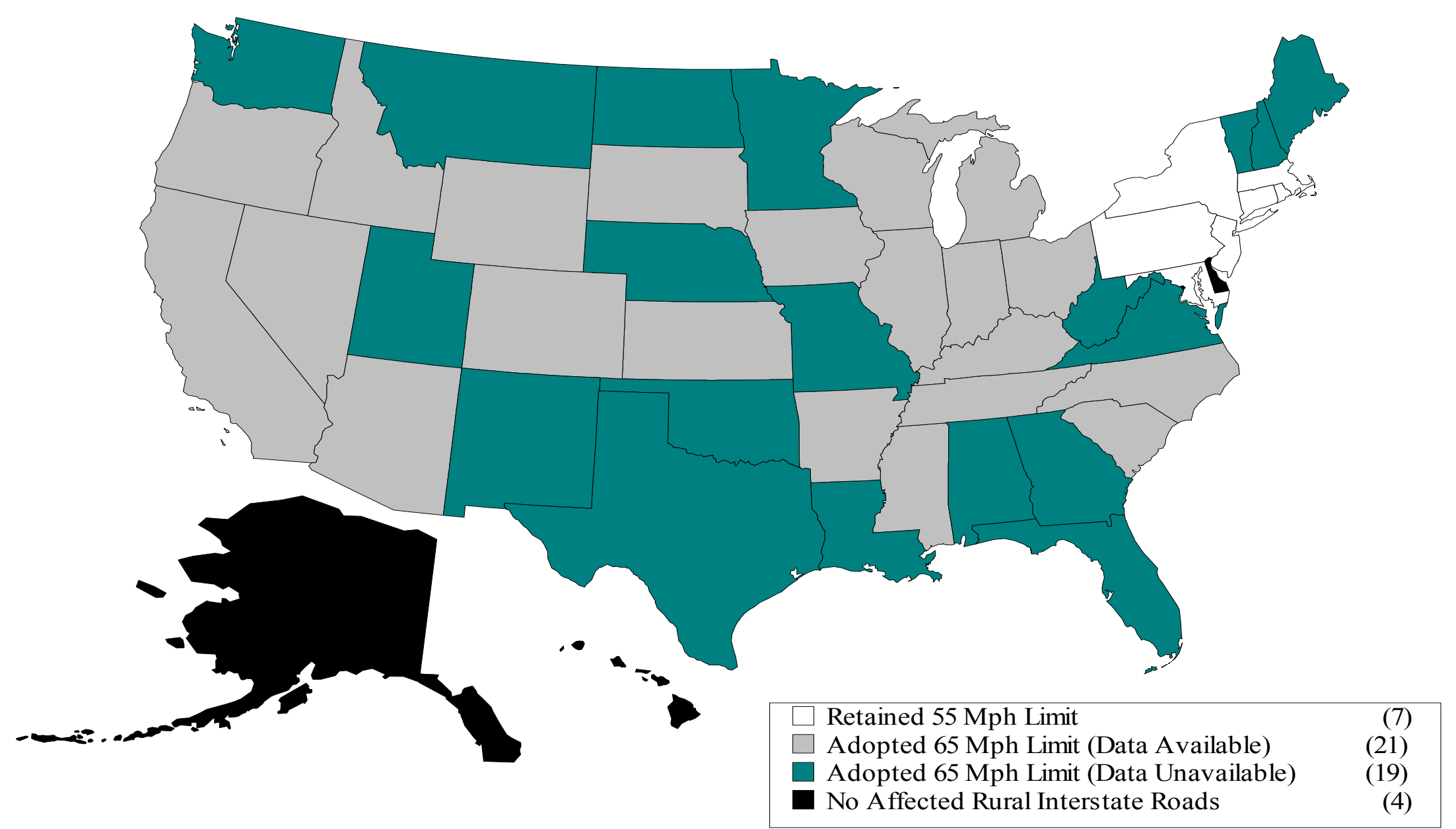


Figure 3: Trends in Fatality Rates on Rural Interstate Roads, by Adoption of 65 Mph Speed Limit, 1982-93

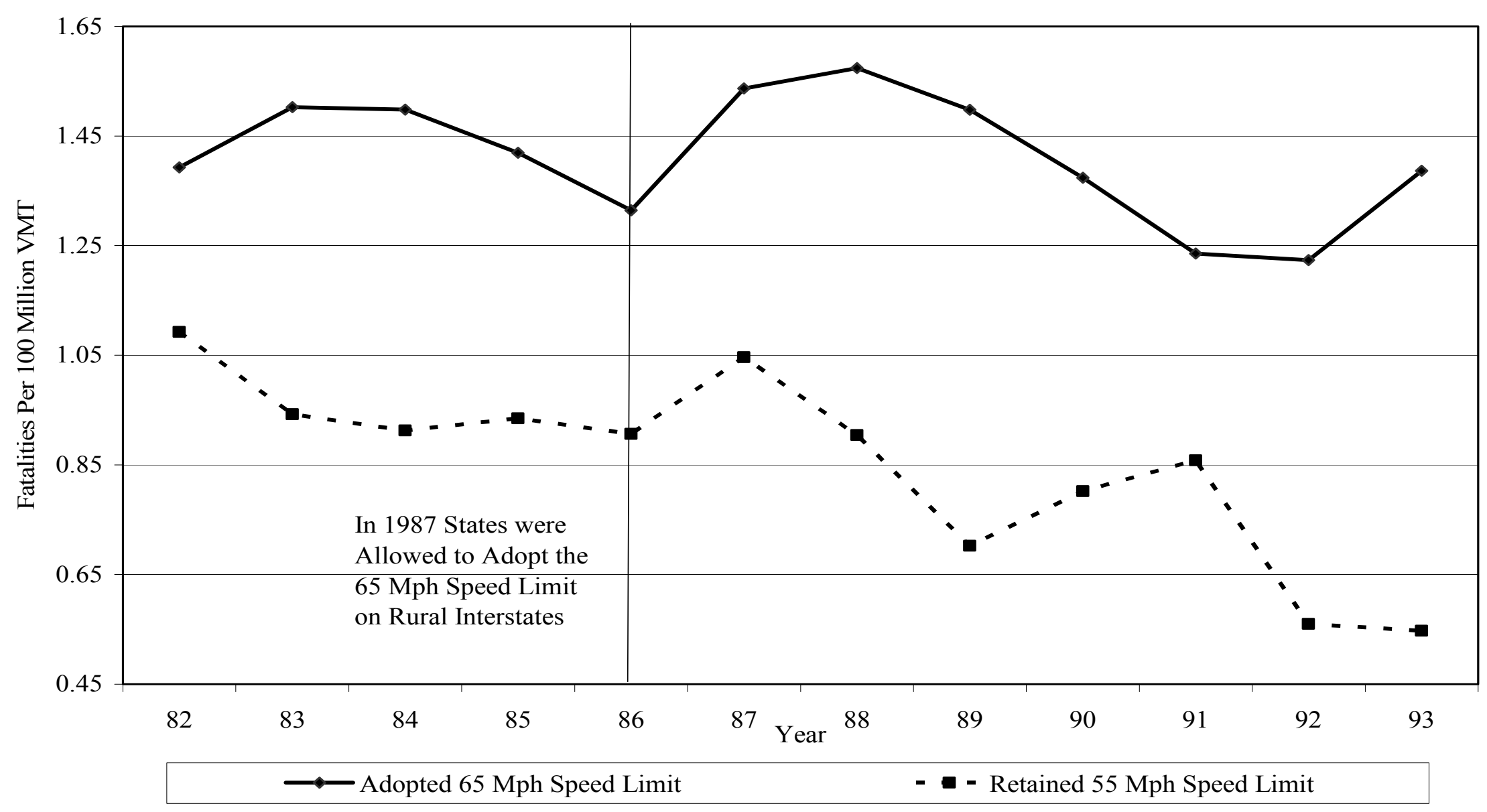

Notes: The fatality rate is calculated as the weighted mean of the number of fatalities per 100 million vehicle miles of travel, where the weight is vehicle miles of travel. 
Figure 4: Trends in Mean Speeds on Rural Interstate Roads, by Adoption of 65 Mph Speed Limit, 1982-93

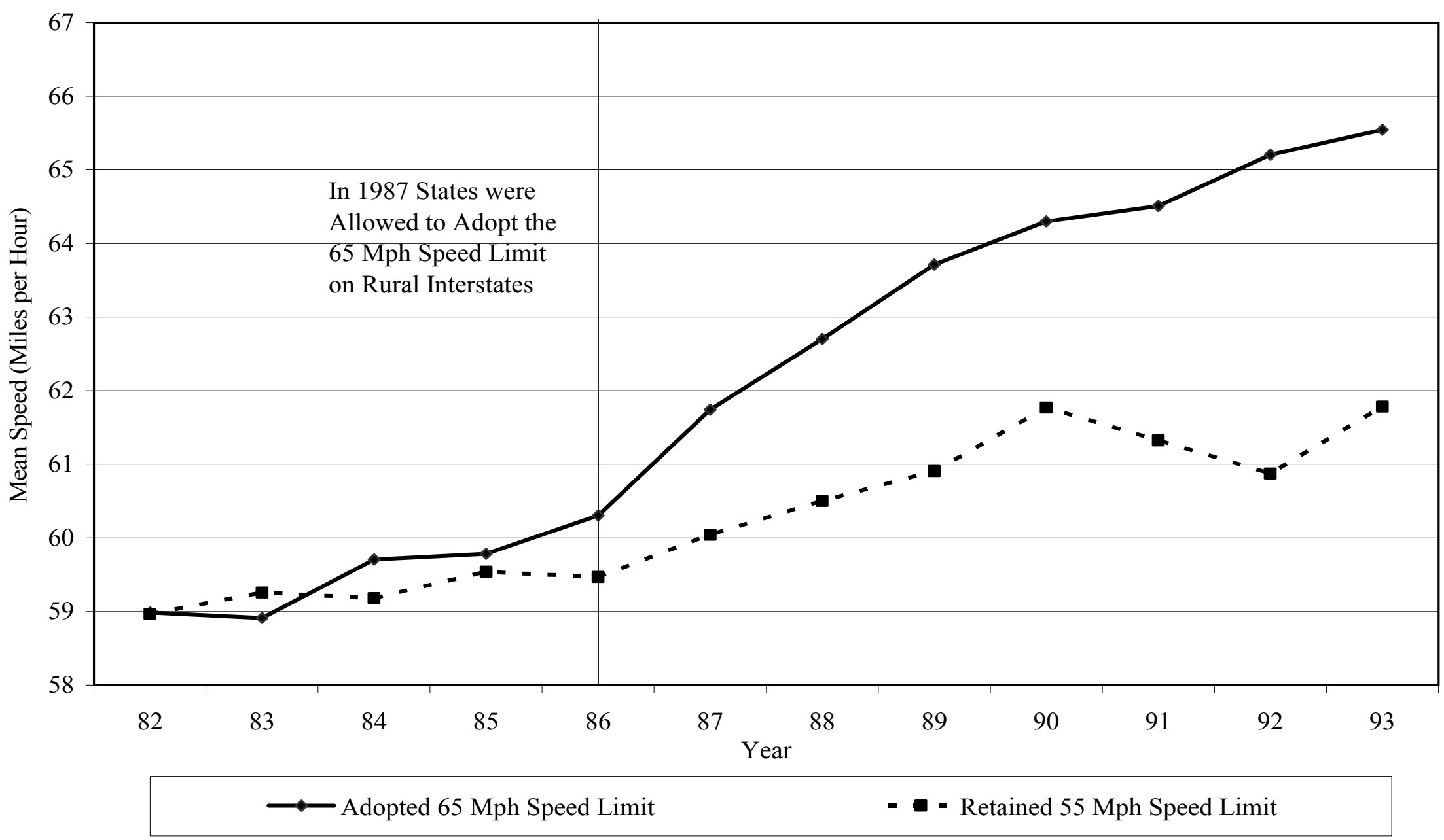

Notes: Mean speed is calculated as the weighted mean, where the weight is vehicle miles of travel. 